
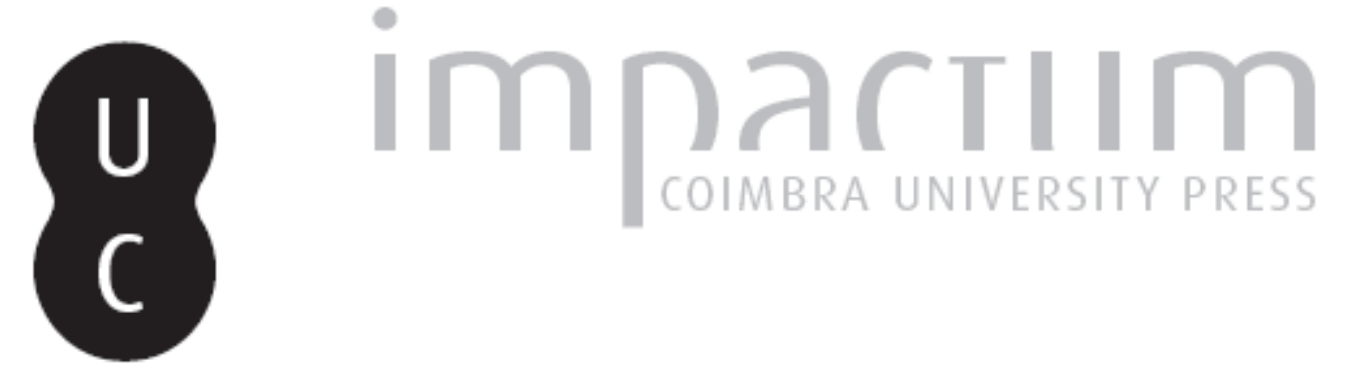

\title{
Análise da suscetibilidade ao desprendimento de blocos rochosos nas arribas da orla costeira do Algarve: aplicação do método Rock Engineering System (RES)
}

Autor(es): $\quad$ Viegas, José; Pais, Luís Andrade

Publicado por: $\begin{aligned} & \text { Associação Portuguesa de Riscos, Prevenção e Segurança; Imprensa } \\ & \text { da Universidade de Coimbra }\end{aligned}$

URL

persistente:

URI:http://hdl.handle.net/10316.2/41208

DOI:

DOI:https://doi.org/10.14195/1647-7723_24_3

Accessed : $\quad$ 26-Apr-2023 15:11:37

A navegação consulta e descarregamento dos títulos inseridos nas Bibliotecas Digitais UC Digitalis, UC Pombalina e UC Impactum, pressupõem a aceitação plena e sem reservas dos Termos e Condições de Uso destas Bibliotecas Digitais, disponíveis em https://digitalis.uc.pt/pt-pt/termos.

Conforme exposto nos referidos Termos e Condições de Uso, o descarregamento de títulos de acesso restrito requer uma licença válida de autorização devendo o utilizador aceder ao(s) documento(s) a partir de um endereço de IP da instituição detentora da supramencionada licença.

Ao utilizador é apenas permitido o descarregamento para uso pessoal, pelo que o emprego do(s) título(s) descarregado(s) para outro fim, designadamente comercial, carece de autorização do respetivo autor ou editor da obra.

Na medida em que todas as obras da UC Digitalis se encontram protegidas pelo Código do Direito de Autor e Direitos Conexos e demais legislação aplicável, toda a cópia, parcial ou total, deste documento, nos casos em que é legalmente admitida, deverá conter ou fazer-se acompanhar por este aviso. 


\section{MULTIDISCIPLINARIDADE NA ANÁLISE DAS MANIFESTAÇÕES DE RISCO}

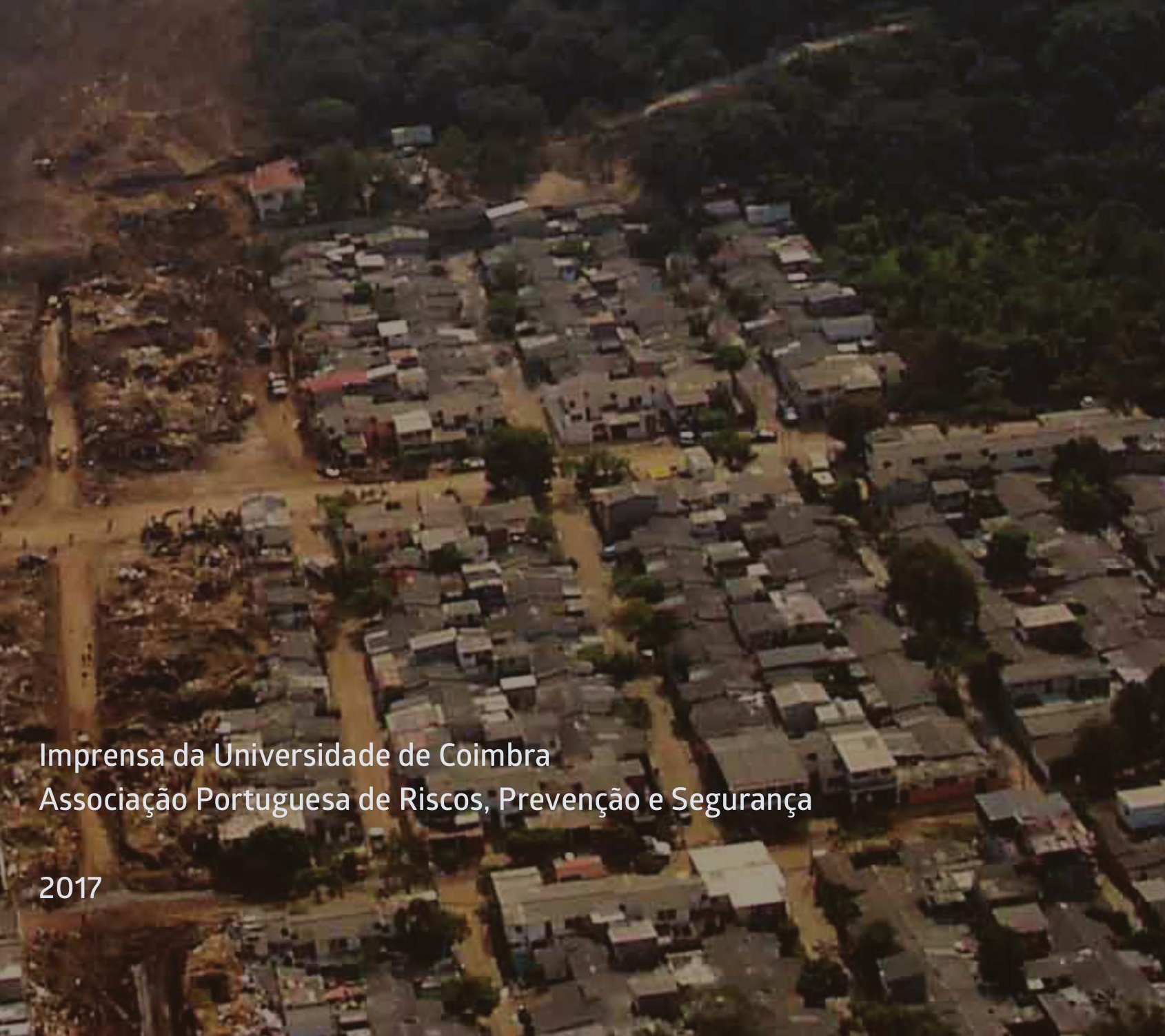




\title{
ANÁLISE DA SUSCETIBILIDADE AO DESPRENDIMENTO DE BLOCOS ROCHOSOS NAS ARRIBAS DA ORLA COSTEIRA DO ALGARVE: APLICAÇÃO DO MÉTODO ROCK ENGINEERING SYSTEM (RES)*
}

\author{
ROCKFALL SUSCEPTIBILITY ANALYSIS IN THE COASTAL CLIFFS OF ALGARVE: AN APPLICATION OF THE \\ ROCK ENGINEERING SYSTEM (RES) METHOD
}

José Viegas

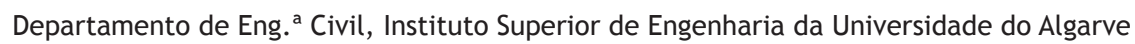
jviegas@ualg.pt

Luís Andrade Pais

Departamento de Eng. ${ }^{a}$ Civil e Arquitetura / Universidade da Beira Interior

ljap@ubi.pt

\section{RESUMO}

O presente trabalho tem como objetivo apresentar uma aplicação do método Rock Engineering System, com vista à avaliação da instabilidade potencial das arribas rochosas da orla costeira do Algarve, que evoluem através de eventos de movimentos de massa intermitentes e descontínuos. Identificam-se os parâmetros que desempenham um papel mais relevante no comportamento das arribas, quantificam-se as interações binárias e o coeficiente de ponderação dos parâmetros principais, e calcula-se o índice de instabilidade das arribas de alguns setores costeiros.

Palavras-chave: Arribas rochosas, instabilidade, matriz de interação.

\section{ABSTRACT}

This paper presents an application of Rock Engineering System method in an attempt to reveal and assess the inherent instability potential along the Algarve rocky coast, which evolves through intermittent and discontinuous events of slope mass movements. The main objective has been defining the principal causative and triggering factors responsible for the manifestation of cliff instability, quantify their interactions, obtain their weighted coefficients, and calculate the instability index, which refers to the inherent potential instability of each coastal cliff.

Keywords: Rocky sea cliffs, instability, interaction matrix.

\section{RESUMEN}

Análisis de la susceptibilidad por desprendimientos de rocas en los acantilados costeros del Algarve: Aplicación del método rock engineering sytem (RES) - El presente trabajo tiene como objetivo presentar una aplicación del método Rock Engineering System, con el fin de evaluar la inestabilidad potencial de la costa rocosa del Algarve, que evoluciona mediante movimientos de ladera intermitentes y discontinuos. Se identifican los parámetros que juegan un papel más importante en el comportamiento de los acantilados, se cuantifican las interacciones binarias entre los principales parámetros y el índice de inestabilidad de algunos acantilados rocosos.

Palabras clave: Acantilados rocosos, inestabilidad, matriz de interacción.

\section{RESUMÉ}

Analyse de la susceptibilité aux chutes de masses rocheuses dans les falaises de la côte de l'Algarve: Application de la méthode rock engineering system (RES) - Ce travail vise à présenter une application de la méthode Rock Engineering System en vue d'évaluer l'instabilité potentielle des falaises rocheuses de la côte de l'Algarve, qui évoluent à travers des événements intermittents et discontinues de mouvements de masse. L'objectif principal a été d'identifier les principaux facteurs qui gouvernent le comportement des falaises, de quantifier les interactions binaires, et de calculer l'indice d'instabilité des falaises dans certains secteurs du littoral rocheux analysé.

Mots-clé: Falaises rocheuses, instabilité, matrice d'interaction.

* O texto deste artigo corresponde a uma comunicação apresentada no I Seminário da Rede Incêndios-Solo e I Simpósio Ibero-Afro-Americano de Riscos, tendo sido submetido em 29-11-2015, sujeito a revisão por pares a 09-01-2016 e aceite para publicação em 05-04-2016.

Este artigo é parte integrante da Revista Territorium, n. ${ }^{\circ} 24,2017,{ }^{\circ}$ RIscos, ISSN: 0872-8941. 
Introdução

As zonas costeiras rochosas caracterizam-se pelo predomínio de afloramentos do substrato rochoso, onde os aspetos morfológicos mais distintivos são a existência de arribas, plataformas litorais e praias de pequena dimensão, apresentando dinâmicas e tempos de resposta claramente diferenciados dos ambientes onde predominam sedimentos não consolidados (A. S. Trenhaile, 1997).

Nas zonas costeiras alcantiladas a erosão dá lugar à desintegração granular, descompressão, desarticulação e eventos de instabilidade por movimentos de massa nos maciços expostos pelas arribas, sendo a incidência espacial e a severidade destes eventos controlada pela morfologia, propriedades geomecânicas dos maciços rochosos e interações com as condições ambientais.

A morfodinâmica natural das arribas processa-se através de uma sequência descontínua e intermitente de movimentos de massa, de difícil previsão espacial e temporal, podendo apresentar diferentes tipologias e magnitude/intensidade. Em geral, os movimentos de grande volume (dezenas de milhares de metros cúbicos de material) e suscetíveis de provocar recuos instantâneos da linha de costa da ordem da dezena de metros, apresentam uma baixa frequência de ocorrência, enquanto que os pequenos desprendimentos de blocos rochosos, decimétricos e de difícil identificação, apresentam frequências relativamente elevadas (e.g., C. Dussauge-Peisser et al., 2002).

Os desprendimentos e os colapsos são os tipos de eventos de instabilidade mais frequentes; os quais, pelo facto de se processarem com velocidades elevadas e poderem atingir grandes alcances, podem acarretar um risco elevado para indivíduos e bens expostos em zonas de praia delimitadas por arribas subverticais. Com o progressivo desenvolvimento do turismo nas áreas balneares, há uma necessidade crescente de avaliação da perigosidade e do risco destes processos de instabilidade, com vista à adoção e aplicação de medidas de proteção de indivíduos, edificações e infraestruturas.

As zonas costeiras constituem um dos sistemas mais dinâmicos da natureza, encontrando-se submetidas a processos de origem contrastante (continental, oceânica e atmosférica) e atuantes em diferentes escalas temporais, experimentando alterações em resposta a modificações cíclicas das condições ambientais, ou com uma forte componente estocástica. A quantificação da influência e da importância relativa dos parâmetros suscetíveis de condicionarem o comportamento da costa rochosa alcantilada, bem como o entendimento das interações existentes, não é uma tarefa fácil, tendo para tal sido aplicado o método Rock Engineering System.

\section{Enquadramento da área de estudo}

A costa Sul de Portugal, localizada na extremidade ocidental do Sul da Europa, tem um clima tipicamente mediterrânico, com verões quentes e secos e invernos amenos. A precipitação média anual é da ordem de 500 a $600 \mathrm{~mm}$, concentrando-se cerca de $80 \%$ deste valor na estação húmida (de outubro a março).

O clima de agitação marítima da costa Sul caracterizase por uma altura significativa da onda com um valor médio de $1 \mathrm{~m}$, sendo menos de $2 \%$ dos valores superiores a $3 \mathrm{~m}$. No verão (abril a setembro), o número médio de dias com temporal é de 0.6 , ao passo que no inverno marítimo (outubro a março) esse valor sobe para 9.6 (Costa et al., 2001).

O setor da orla costeira objeto de estudo situa-se no litoral rochoso do Barlavento Algarvio, entre a Praia do Porto de Mós e a Praia dos Olhos de Água, com uma extensão de cerca de $46 \mathrm{~km}$ de arribas (fig. 1). As arribas rochosas deste setor da orla costeira expõem, maioritariamente, a Formação Carbonatada de Lagos-Portimão, de idade Miocénica, constituída por intercalações de calcarenitos fossilíferos, calcarenitos finos, calcários cristalinos e siltitos, fortemente carsificados.

A fração carbonatada é dominante nos materiais estudados. Nos calcarenitos finos varia, em média, entre 60 e 75\%, podendo os materiais menos litificados apresentar valores mínimos da ordem de 50\%; ao passo que os calcarenitos fossilíferos apresentam valores médios superiores a $80 \%$.

Nos setores onde o efeito da carsificação se faz sentir com maior intensidade, os maciços expostos apresentam um grau de fraturação elevado, porosidade secundária e dissolução intergranular, dando origem à formação de vazios alveolares, textura fenestrada e crostas de deposição de carbonatos. É disso exemplo o setor costeiro compreendido entre a Praia de São Rafael e a Praia do Castelo, no concelho de Albufeira, ao longo do qual se pode observar, invariavelmente, um amontoado de blocos rochosos junto da base das arribas, resultantes da ocorrência de eventos de instabilidade potenciados pelos processos de alteração, dissolução, infraescavação basal e descompressão dos maciços.

A altura das arribas pode atingir os $40 \mathrm{~m}$, com as formações carbonatadas a apresentar estratificação horizontal ou levemente inclinada para S e SE, exceto nas imediações das principais estruturas tectónicas da região, como é o caso da falha Portimão e do diapiro de Albufeira, onde a inclinação da estratificação é mais elevada, variando entre $10^{\circ}$ e $20^{\circ}$. O facto da inclinação dos planos de estratificação ser, em geral, inferior a $20^{\circ}$, é favorável à estabilidade das arribas, tornando pouco provável a ocorrência de deslizamentos translacionais planares. 


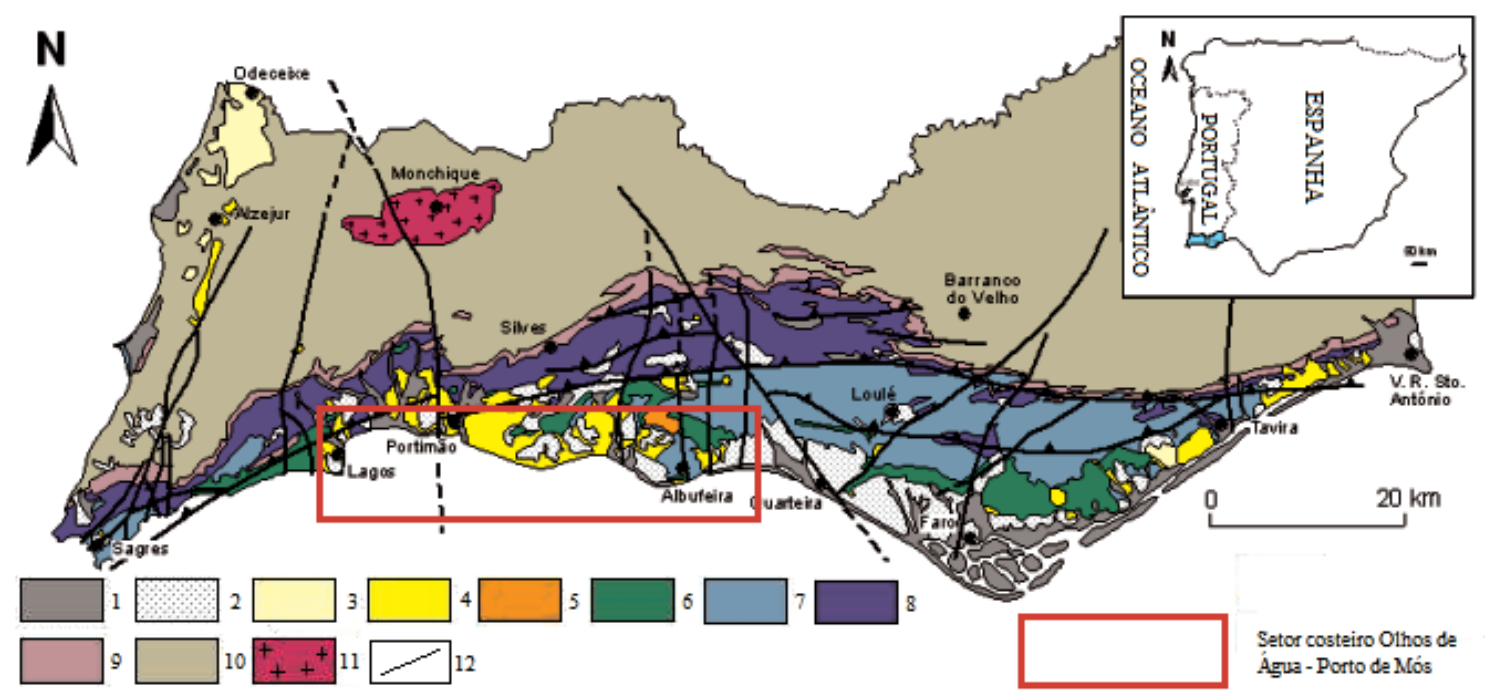

1- Holocénico; 2- Pleistocénico; 3- Pliocénico; 4- Miocénico; 5- Paleogénico; 6- Cretácico Inferior; 7- Jurássico Superior; 8- Jurássico Médio - Inferior; 9- Hetangiano - Triásico Superior; 10-Soco Paleozoico; 11- Complexo alcalino de Monchique; 12- Falhas.

Fig. 1 - Área de estudo, situada no litoral rochoso do Barlavento Algarvio, entre a Praia do Porto de Mós e a Praia dos Olhos de Água (Fonte: adaptado da carta geológica de Portugal 1/500000).

Fig. 1 - Location of the study area on the rocky coast of the Barlavento of Algarve, between Porto de Mós beach and the Olhos de Água beach (Source: adapted from the geological map of Portugal, scale 1/500000).

Na imediação do diapiro de Albufeira, o setor da orla costeira compreendido entre o lado nascente da praia dos Arrifes e a Marina de Albufeira expõe calcários dolomíticos e margas do Cretácico, que, de forma atípica, apresentam estratificação subvertical. Quando a estratificação subvertical é paralela à face da arriba, a suscetibilidade à ocorrência de eventos de instabilidade por basculamentos de blocos é elevada, facto que é testemunhado pela presença de um grande número de blocos depositados junto da base da arriba. Uma vez que, a velocidade das deformações registadas na fase inicial destes movimentos é relativamente lenta, são de movimentos relativamente previsíveis e com menor perigosidade do que os desprendimentos.

Segundo o inventário que tem vindo a ser realizado pela Agência Portuguesa do Ambiente (S. B. Teixeira, 2014), entre julho de 1995 e junho de 2014, registaram-se 244 eventos de instabilidade por movimentos de massa, correspondentes a uma frequência média de 13 eventos/ano, com um valor mínimo de 2 eventos/ano e um valor máximo de 42 eventos/ano. Relativamente à tipologia dos movimentos, $63 \%$ correspondem a quedas ou desprendimentos, $21 \%$ são basculamentos e $16 \%$ correspondem a colapsos em cavidades cársicas.

Cerca de $83 \%$ dos eventos de instabilidade tiveram lugar durante a estação húmida (novembro a abril), mostrando uma clara sazonalidade dos movimentos de massa registados. Quando é conhecido o dia em que a rotura ocorreu, cerca de $50 \%$ desses eventos de instabilidade coincidiram com tempestades marítimas (com altura significativa superior a
$2.5 \mathrm{~m}$ ) ou precipitações diárias superiores a $10 \mathrm{~mm}$. Cerca de $78 \%$ das roturas ocorreram nos 5 dias posteriores à dada de ocorrência do evento desencadeante de natureza meteorológica (S. B. Teixeira, 2014), havendo uma resposta diferida da arriba à solicitação extrema.

Embora se trate de eventos característicos da estação húmida, podem ocorrer roturas durante o período estival (quando o número de indivíduos expostos nas zonas de praia é mais elevado), sem que a sua ocorrência esteja explicitamente ligada a qualquer solicitação desencadeante de natureza meteorológica extrema. Nestes casos, a rotura ocorre em resultado da degradação progressiva dos maciços, por processos sucessivos de molhagem/secagem, variações térmicas, infraescavação e descompressão, sendo difícil identificar o processo predominante no desencadear da rotura.

\section{Considerações sobre a suscetibilidade e perigosidade à queda de blocos rochosos na zona costeira}

A suscetibilidade representa a propensão para uma dada área ser afetada por um evento de instabilidade por movimento de massa, em tempo indeterminado, sendo avaliada através dos fatores de predisposição (entenda-se condicionantes) para a ocorrência de movimentos, sem contemplar o seu período de retorno ou a probabilidade de ocorrência. É, portanto, a componente espacial da avaliação da perigosidade (S. Greiving et al., 2014)

A perigosidade corresponde à probabilidade de ocorrência de um movimento de massa com potencial destruidor (ou 
para provocar danos) de uma determinada severidade, numa dada área e num dado período de tempo. A avaliação da perigosidade requer, não só a avaliação da suscetibilidade à ocorrência de eventos de instabilidade na área em estudo, incluindo a localização, o volume (ou área), a tipologia, a velocidade e o alcance expectável do movimento, mas também a determinação da frequência expetável (e.g., probabilidade anual) e da probabilidade de propagação (ou de impacto espacial), incluindo a análise dos eventos de instabilidade com origem em áreas adjacentes, que podem alcançar ou regredir até à área que está sendo objeto de zonamento (AGS, 2007; JTC-1, 2008; R. Fell et al., 2008). Desta forma, os mapas de zonamento da perigosidade, para além de indicarem onde um evento pode ocorrer, também têm informação sobre quando e como pode ocorrer o movimento, sendo a componente temporal a característica fundamental e distintiva deste tipo de mapas (S. Greiving et al., 2014).

Numa arriba, o processo de desprendimento dos blocos rochosos pode ser dividido em duas partes: a primeira, corresponde à instabilidade ou rotura na área fonte; a segunda, corresponde à área de alcance dos blocos a uma determinada distância (fig. 2). A perigosidade (H (E, x)) num dado ponto $x$, para uma determinada energia cinética $(E)$ dos blocos, é obtida através do produto da probabilidade média (ou frequência) de rotura do maciço rochoso $\left(l_{f}\right)$ pela probabilidade de propagação $\left(P_{p}\right)$ até ao ponto $\times$ (Groupe falaise, 2001; M. Jaboyedoff et al., 2005):

$$
H(E, x)=\lambda_{f} x P_{p}(E, x)
$$

A probabilidade de ocorrência e a intensidade dependem da magnitude (volume) inicial dos desprendimentos, pelo que a perigosidade deve ser estimada para diferentes cenários de magnitude, explícita ou implicitamente associados a diferentes períodos de retorno. Em geral, os eventos de instabilidade de maior magnitude apresentam uma menor frequência de ocorrência (C. DussaugePeisser et al., 2002) e uma maior energia cinética (J. M. Vengeon et al., 2001).

Enquanto a probabilidade de rotura de uma arriba $\left(\lambda_{f}\right)$ corresponde à probabilidade de ocorrência de um desprendimento de determinado volume de maciço rochoso, por unidade de tempo; a probabilidade de propagação (probability of propagation $-P_{p}$ ) ou probabilidade de impacto espacial (spacial probability) corresponde à probabilidade de uma determinada porção do maciço rochoso, com determinadas características, atingir um determinado local a jusante (Groupe falaise, 2001). Portanto, a perigosidade pode ser expressa como o número de desprendimentos/ano que podem alcançar ou atravessar a área cartografada, por km de arriba (C. J. van Westen, 2011).

A avaliação da perigosidade à ocorrência de desprendimentos de blocos rochosos desenvolve-se ao longo das seguintes etapas:
- Identificação das áreas fonte de desprendimentos de blocos rochosos;

- Análise da magnitude dos eventos;

- Avaliação da frequência dos desprendimentos de blocos rochosos;

- Análise da trajetória, alcance e probabilidade de propagação dos blocos.

O zonamento da suscetibilidade e da perigosidade a movimentos de massa, também designado por cartografia de movimentos em massa potencialmente perigosos ( $L$. Lourenço,2007; F. Rebelo, 2010), não é uma ciência exata e os resultados obtidos correspondem tão-somente a uma previsão do comportamento das arribas com base nos dados disponíveis, existindo um número elevado de potenciais fontes de erro, nomeadamente, devido a:

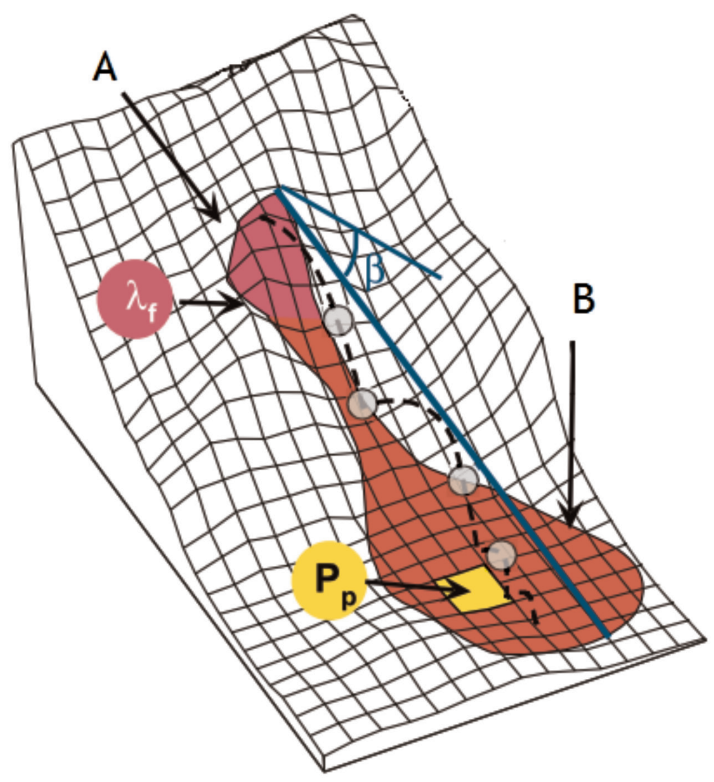

Fig. 2 - Avaliação da perigosidade à queda de blocos rochosos. $\lambda_{f}$ é a frequência média de desprendimentos e Pp a probabilidade de propagação até à área amarela. A azul, o ângulo $B$ corresponde ao ângulo sombra .

A - Local da instabilidade (fonte): tipo de instabilidade, caraterísticas e probabilidade de rotura;

B - Zona de propagação: Perímetro de propagação da queda de blocos, caraterísticas, probabilidade de propagação e perigosidade. (Fonte: M. Jaboyedoff et al., 2005).

Fig. 2 - Rockfall hazard evaluation. $\lambda_{f}$ is the rock mass failure mean frequency and $P_{p}$ the probability of propagation up to the yellow area. In blue, the shadow angle $B$.

$A$ - Instabilities: Instability type, characteristics and failure probability;

B - Propagation zone: perimeter of rockfall propagation, characteristics, probability of propagation and hazard. (Source: M. Jaboyedoff et al., 2005). 
- Limitações no inventário dos movimentos de massa, que servem de base à cartografia de suscetibilidade e de perigosidade;

- Limitações na consistência das séries temporais (e.g., precipitação e agitação marítima);

- Limitações ao nível do detalhe disponível da topografia, geomorfologia e caracterização geotécnica das formações;

- Incertezas no modelo de zonamento utilizado, devido a limitações nos métodos utilizados para relacionar os eventos desencadeantes com o inventário, a topografia, geomorfologia e as características geológico-geotécnicas das formações.

O facto do recuo das arribas resultar de uma série complexa de eventos de instabilidade, de difícil previsão, dificulta a monitorização e conduz a um importante grau de incerteza na avaliação da probabilidade de rotura (ou frequência). Muitas vezes, os intervalos de tempo registados entre os eventos de instabilidade são variáveis, dependendo da sequência de tempestades marítimas e da condição de estabilidade da arriba no momento da sua ocorrência. Se, num dado momento, a condição de estabilidade da arriba é elevada, a ocorrência de um determinado evento desencadeante potencial (e.g., tempestade marítima) de intensidade elevada pode não desencadear qualquer tipo de instabilidade. Com o decorrer do tempo, a condição de estabilidade da arriba tende a diminuir devido à ação de fatores preparatórios (e.g., infraescavação basal por abrasão marinha e processos de alteração física e química dos maciços), e a ocorrência de uma nova tempestade, com intensidade igual ou mesmo inferior às anteriormente registadas, pode, neste caso, desencadear eventos de recuo da arriba por movimentos de massa (E. M. Lee et al., 2001; Eurosion, 2004; E. M. Lee \& D. K. C. Jones, 2004). Portanto, a resposta de uma arriba a um determinado evento desencadeante potencial é controlada pela sua condição de estabilidade, ou seja, depende da sua história recente (E. M. Lee et al., 2001).

Quando o maciço exposto apresenta blocos soltos e numa condição de estabilidade precária (fot. 1), a ação de um evento desencadeante de natureza atmosférica ou sísmica, pode, a todo o momento, com um elevado grau de probabilidade, provocar o desprendimento e a queda desses blocos, aumentando a partir desse momento a condição de estabilidade da arriba.

Assim, pese embora os eventos de instabilidade se correlacionem positivamente com a ocorrência de tempestades marítimas, o grau de correlação depende da condição de estabilidade da arriba no momento da ocorrência da tempestade. Quando a probabilidade de rotura de uma arriba é determinada a partir de movimentos de massa pretéritos, registados ao longo de períodos de tempo curtos, a probabilidade de rotura assim calculada pode não refletir minimamente a evolução das arribas a médio ou longo prazo. O período de retorno dos eventos de instabilidade depende de características específicas de cada setor da orla costeira. Arribas talhadas em maciços competentes tendem a apresentar uma maior
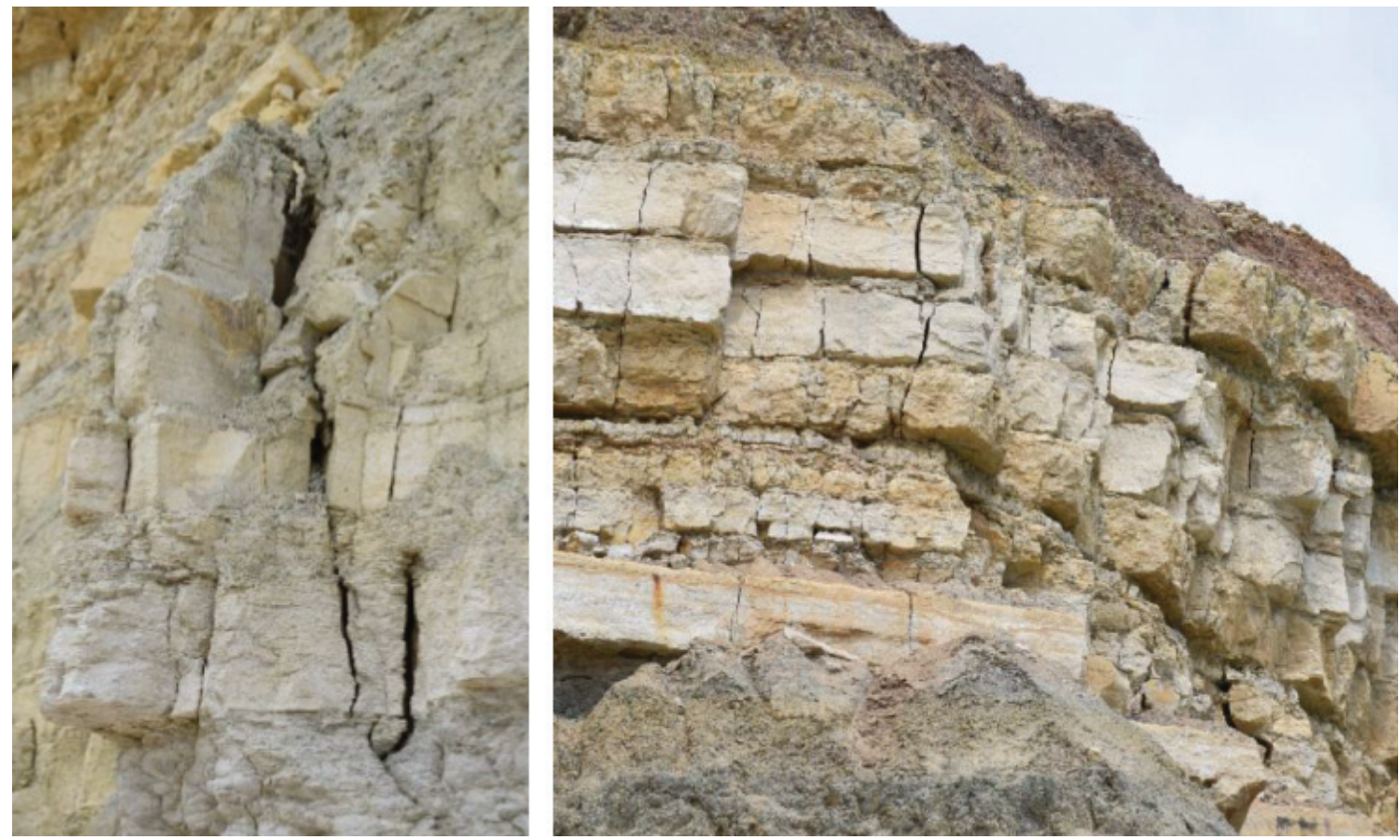

Fot. 1 - Blocos rochosos soltos numa situação de equilíbrio limite.

Photo 1 - Loose boulders in limit equilibrium. 
resiliência a eventos extremos, ao passo que as arribas talhadas em rochas brandas respondem imediatamente aos eventos de elevada energia, apresentando períodos de retorno muito inferiores.

Por outro lado, também é importante ter em conta que, a ocorrência de eventos de instabilidade por movimentos de massa, por vezes, pode não estar explicitamente ligada a qualquer solicitação gerada pelos fatores desencadeantes externos mais frequentes (e.g., tempestades marítimas e períodos de precipitação elevada), podendo ocorrer em resultado da fadiga provocada pela degradação progressiva dos maciços por processos sucessivos de saturação/secagem, variações de temperatura e alteração química, sendo difícil avaliar qual é o processo predominante no desencadear da rotura, que pode ocorrer durante o período estival.

\section{Metodologia}

Identificação dos fatores que influenciam a estabilidade

Os movimentos de massa são processos gravitacionais suscetíveis de ocorrerem devido ao incremento da atuação de forças desestabilizadoras e/ou através da redução da resistência dos maciços expostos.

Uma arriba é estável quando as forças resistentes, que contrariam o movimento, são superiores às desestabilizadoras, considerando-se que a arriba apresenta uma determinada margem de estabilidade (ou coeficiente de segurança). No momento da rotura, pelo facto das forças desestabilizadoras igualarem as resistentes, a margem de estabilidade anula-se, ocorrendo o movimento de massa, com o material a deslocar-se até uma nova posição de equilíbrio que restabeleça o balanço entre as forças desestabilizadoras e resistentes (E. M. Lee \& Jones, 2004). Nas zonas costeiras, a infraescavação basal promovida pela abrasão marinha e os processos de meteorização reduzem a condição de estabilidade das arribas, fazendo com que as forças que contrariam o movimento sejam excedidas pelas forças desestabilizadoras.

São muitos os fatores responsáveis pela ocorrência, frequência, tipologia e magnitude/intensidade dos eventos de instabilidade e, muitas vezes, aquando da atuação dos fatores desencadeantes, a arriba já se encontra numa condição de equilíbrio limite (M. Popescu, 1994; J. Corominas et al., 2013). Esta grande diversidade de fatores dificulta a análise da suscetibilidade e da perigosidade dos movimentos de massa, de tal forma que num mesmo setor da orla costeira, diferentes combinações de fatores condicionantes podem controlar diferentes tipologias de movimentos e mecanismos de rotura (G. B. Crosta et al., 2012; J. Corominas et al., 2013).
Os fatores que controlam a condição de equilíbrio das arribas da orla costeira podem ser agrupados em 3 conjuntos (M. Crozier et al., 2005):

- Fatores de predisposição (ou “passivos”): são estáticos e inerentes às características dos maciços (e.g., fatores geométricos ou morfológicos, litológicos, hidrogeológicos, geo-técnicos), condicionando o grau de instabilidade potencial da arriba e determinando a variação espacial do grau de suscetibilidade da arriba à ocorrência de eventos de instabilidade. No caso de maciços rochosos competentes, o fator condicionante preponderante tende a ser a estrutura geológica.

- Fatores preparatórios (ou “dinâmicos”): são lentos e contínuos, promovendo o decréscimo da condição de estabilidade dos maciços ao longo do tempo (e.g., infraescavação basal e processos de alteração química e física), sem despoletar o movimento. Por vezes, sem que ocorra um fator desencadeante de natureza meteorológica, podem desencadear a rotura da arriba. No estado atual do conhecimento, não é possível prever de forma satisfatória a evolução da condição de estabilidade de uma arriba ao longo do tempo, visto ainda ser insuficiente $o$ entendimento quantitativo dos processos físicos e químicos que promovem o progressivo decréscimo da sua condição de estabilidade (D. Hantz, 2007).

- Fatores desencadeantes (ou “ativos”): correspondem a processos rápidos e descontínuos, que representam a causa imediata da instabilidade e tendem a determinar o ritmo temporal (frequência) dos movimentos de massa; destes fatores, os mais comuns são as tempestades de inverno, com períodos de precipitação intensa e prolongada (geradoras de pressões intersticiais e forças de percolação), ventos fortes e alturas de onda significativa elevada, coincidentes com a preia-mar de marés vivas.

Com base no trabalho de campo, ensaios in situ e laboratoriais, análises cinemáticas da estabilidade, retroanálises e auscultação da opinião de especialistas, foram considerados 10 parâmetros principais, aos quais se juntou o histórico de eventos de instabilidade, perfazendo um total de 11 parâmetros: altura da arriba (P1); inclinação da arriba (P2); variação vertical de fácies/estratigrafia e litologia $(\mathrm{P} 3)$; resistência à compressão uniaxial da matriz rochosa (P4); alteração e dissolução cársica (P5); número de famílias e espaçamento das descontinuidades (P6); condição das descontinuidades: persistência, rugosidade, abertura e enchimento (P7); orientação das descontinuidades relativamente à orientação da face da arriba (P8); presença de água subterrânea (P9); exposição às ondas (P10) e histórico de eventos de instabilidade (P11). 


\section{Descrição e justificação dos parâmetros selecionados}

\section{Altura da arriba (P1):}

A altura das arribas da orla costeira resulta da ação da atividade tectónica e de processos de erosão e meteorização, sendo a atuação destes últimos influenciada pelas condições ambientais atuais e pretéritas.

Nas arribas mais altas, os maciços encontram-se sujeitos a estados de tensão mais elevados e, em geral, apresentam uma maior suscetibilidade à ocorrência de eventos de instabilidade. A energia potencial dos blocos rochosos aumenta com a altura da arriba; logo, a perigosidade relativamente à queda de blocos correlaciona-se positivamente com a altura.

\section{Inclinação da arriba (P2):}

A estabilidade das arribas é fortemente condicionada pela sua inclinação. Quando a inclinação aumenta, as forças derrubantes e deslizantes que atuam sobre os blocos rochosos também aumentam; por conseguinte, a suscetibilidade à ocorrência de eventos de instabilidade tende a ser mais elevada nas arribas que apresentam maiores declives.

Variação vertical de fácies (estratigrafia e litologia) (P3):

A variação vertical de fácies, com alternância de materiais de diferente litologia e competência, tem uma influência significativa sobre o perfil transversal da arriba, a taxa de erosão e a tipologia da instabilidade. Quando as arribas expõem formações sedimentares estratificadas, exibindo uma grande heterogeneidade em termos de características de resistência e de durabilidade, os distintos estratos respondem de forma diferenciada aos processos de meteorização e erosivos, e as arribas tendem a apresentar um perfil transversal muito irregular, com os estratos mais competentes posicionados em consola relativamente aos estratos constituídos por materiais mais brandos (USGS, 2004).

O descalce dos estratos mais competentes, gerado pela erosão diferencial, provoca um acréscimo das tensões de tração nesses estratos, devido ao peso próprio da porção de material colocada em consola. Quando o acréscimo das tensões de tração é elevado e as tensões instaladas superam a resistência à tração dos estratos em consola, dá-se a rotura e individualização de blocos, com a consequente ocorrência de desprendimentos. Regra geral, este tipo de eventos de instabilidade tem como fatores desencadeantes as pressões intersticiais geradas pela pluviosidade, a agitação marítima, o crescimento de vegetação e as ações dinâmicas (sísmicas ou antrópicas).
Resistência à compressão uniaxial da matriz rochosa (P4):

A resistência à compressão uniaxial da matriz rochosa é um parâmetro importante na caraterização da resistência e qualidade dos maciços rochosos, sendo utilizado em grande parte dos sistemas de classificação aplicáveis a taludes rochosos (L. Pantelidis, 2009).

Quando as arribas expõem rochas brandas (e.g., siltitos e calcarenitos pouco litificados, com resistência à compressão uniaxial entre 0.25 e $25 \mathrm{MPa}$ ), a relativamente rápida degradação das suas propriedades mecânicas conduz a maiores taxas de erosão e a uma mais elevada frequência de eventos de instabilidade (e.g., Praia Maria Luísa, em Albufeira), com as superfícies de rotura a apresentar, muitas vezes, um controlo estrutural limitado, sem uma estrita relação com os planos de descontinuidade.

Os mecanismos que promovem a variação de resistência nos calcarenitos estão relacionados com a existência de dois tipos distintos de ligações entre os grãos, do tipo temporário e do tipo persistente (diagenéticas). As primeiras, caracterizam-se por poderem ser facilmente removidas e reconstruídas durante as fases de molhagem e secagem, respetivamente, em que a saturação leva à rápida dissolução do cimento das ligações entre os grãos, tornando-se materiais friáveis. Com a secagem, o efeito da capilaridade resultante da tensão superficial contribui para o restabelecimento dessas ligações, voltando a apresentar ganhos de resistência. As segundas ligações, em materiais com maior grau de litificação, só podem ser substancialmente removidas a longo prazo, através de processos de alteração e dissolução química (M. 0 . Ciantia et al., 2014).

Quando as arribas expõem maciços competentes, a sua resistência mecânica excede a força erosiva da onda atuante na base da arriba, e a erosão ocorre de uma forma muito lenta (da ordem de poucos centímetros a milímetros por século), apresentando perfis subverticais e constituindo promontórios ou permanecendo offshore como pináculos e ilhéus.

Alteração e dissolução das formações carbonatadas (P5):

O desenvolvimento do carso costeiro encontra-se favorecido por processos geoquímicos caraterísticos das zonas litorais, como é o caso das zonas de mistura da água doce com a água marinha, sendo estes processos claramente reforçados pelo facto dos materiais calcareníticos apresentarem uma permeabilidade primária elevada.

Com o decorrer da atuação dos processos de erosão marinha, as cavidades cársicas acabam por ser capturadas e, posteriormente, desmanteladas de forma progressiva, desempenhando, assim, um papel relevante na geração dos movimentos de massa e na definição do traçado da 
linha de costa, que se apresenta muito recortado, como é típico dos litorais rochosos talhados em maciços muito heterogéneos e anisotrópicos (fot. 2 e 3).

O carso define zonas de fraqueza e de concentração de tensões, favoráveis à infiltração e percolação de água, erosão interna e meteorização, facilitando o trabalho da erosão marinha e propiciando a sua coalescência relativamente aleatória à medida que se vão interligando e crescendo de forma tridimensional, acabando por dar lugar à formação de enseadas de pequeno ou médio tamanho, promontórios e leixões.

O desenvolvimento de determinadas morfologias cársticas peculiares, como pináculos, arcos ou cavidades, podem atuar como fatores preparatórios de roturas por basculamento, queda de blocos e colapsos. Devido à sua forma esbelta e alta, os pináculos são estruturas efémeras intrinsecamente instáveis e, quando ocorrem em praias muito frequentadas, o risco de perda de vidas devido à ocorrência de roturas por colapso ou basculamento pode ser elevado.

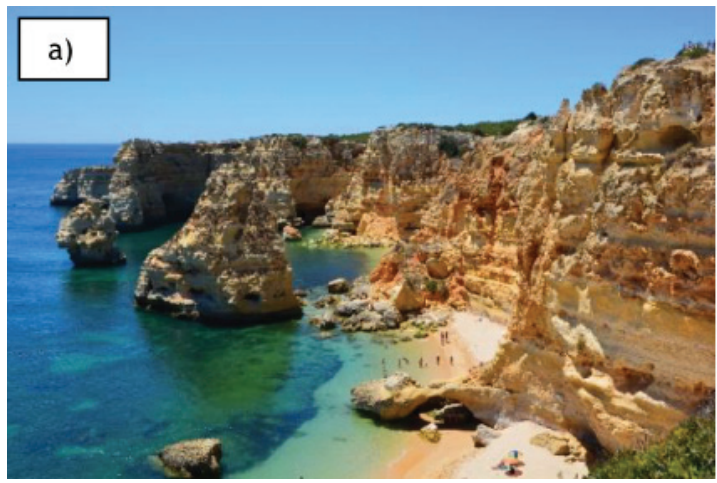

Número de famílias e espaçamento das descontinuidades (P6):

O comportamento dos maciços rochosos competentes é fortemente condicionado pelas características físicas e geométricas das superfícies de descontinuidade que os compartimentam, e ao longo das quais a rotura frequentemente se produz (G. B. Crosta et al., 2012; Geological Society Engineering Group Working Party, 1997; E. Hoek \& J. W. Bray, 1981; R. E. Goodman, 1989).

O número de famílias de superfícies de descontinuidade e a sua orientação e espaçamento determinam a forma e a dimensão dos blocos rochosos (E. Hoek \& J. W. Bray, 1981; J. Corominas, et al., 2013), tendendo a tipologia das instabilidades, bem como a sua probabilidade de ocorrência, para serem ditadas pelo espaçamento e orientação das descontinuidades relativamente à orientação da arriba (G. B. Crosta et al., 2012).

Em geral, a resistência dos maciços rochosos expostos pelas arribas é muito inferior à resistência da matriz

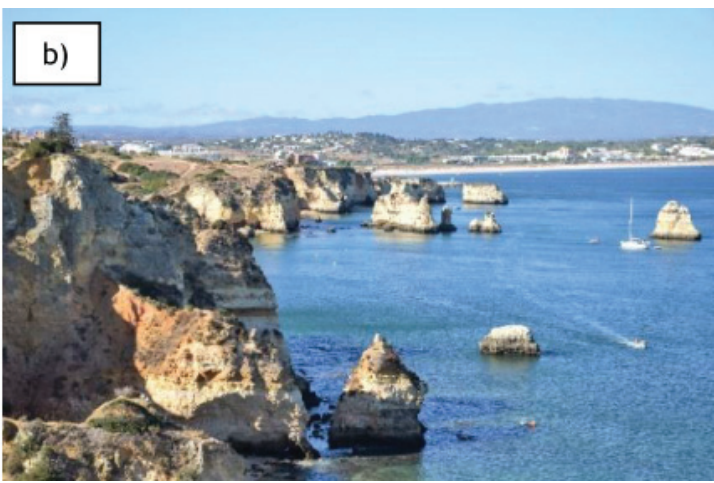

Fot. 2 - Traçado da linha de costa em formações carbonatadas, muito recortado. a) Praia da Marina, no concelho de Lagoa. b) Ponta da Piedade e Praia Dona Ana, no concelho de Lagos.

Photo 2 - The carbonate shore displaying a very crenulated shoreline. a) The Marina Beach in Lagoa. b) Ponta da Piedade and Dona Ana beach in Lagos.
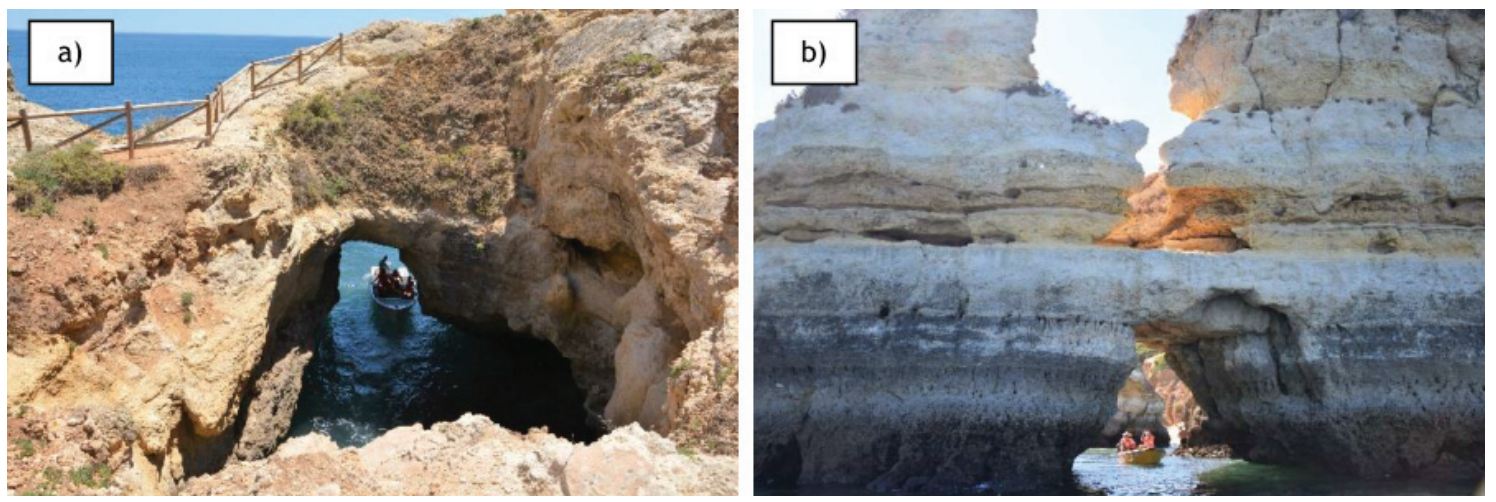

Fot. 3 - Cavidades cársicas localizadas abaixo do nível do mar, atualmente visitáveis por pequenas embarcações turísticas. a) No setor da orla costeira entre a praia da Marinha e a praia de Benagil, no concelho de Lagoa. b) Na Ponta da Piedade, no concelho de Lagos.

Photo 3 - Karstholes located below sea level, visitable by small tourist boats. a) Coastline area between the Marinha beach and the Benagil beach (Lagoa). b) In the Ponta da Piedade area (Lagos). 
rochosa, sendo essa diferença tanto maior quanto maior for o grau de fraturação dos maciços. Desta forma, quando as arribas expõem maciços muito compartimentados, formados por blocos rochosos de reduzido volume, apresentam maior suscetibilidade à ocorrência de eventos de instabilidade por movimentos de massa.

Condição das descontinuidades: persistência, rugosidade, abertura e enchimento (P7)

A condição das descontinuidades, caracterizada pela persistência ou continuidade, rugosidade ou ondulação e abertura ou enchimento, condiciona a resistência ao corte dos maciços, da qual depende a estabilidade das arribas. A magnitude (ou volume) das massas rochosas cinematicamente instáveis é condicionada pela persistência das descontinuidades desfavoráveis; no entanto, trata-se de um parâmetro de difícil quantificação. Muitas vezes, a rotura desenvolve-se ao longo de superfícies cuja continuidade termina contra outro plano de descontinuidade, reduzindo, desta forma, o volume da massa mobilizável. Outras vezes, apresar da interrupção da persistência, a rotura desenvolve-se ao longo de superfícies escalonadas, sendo necessário estudar com detalhe as pontes de rocha (zonas onde as descontinuidades perdem persistência e a rocha se conserva relativamente intacta).

Orientação das descontinuidades relativamente à face arriba (P8)

A orientação das descontinuidades (estruturais ou sedimentares) em relação à orientação da face da arriba tende a ditar a tipologia da rotura (E. Hoek \& J. W. Bray, 1981; R. E. Goodman, 1989), em particular nos casos de rochas duras, onde a rotura é estruturalmente controlada. É caso dos deslizamentos translacionais ao longo de um ou vários planos de descontinuidade de baixa resistência que afloram na face da arriba (e.g., roturas planas e por cunha), ou das roturas através de superfícies escalonadas, requerendo a rotura prévia ou simultânea das pontes de rocha existentes entre descontinuidades subparalelas, e das roturas por movimento relativo de rotação dos blocos em torno de uma aresta, no sentido da face da arriba (roturas por basculamento).

\section{Presença de água subterrânea (P9)}

A presença de água tem, em geral, uma grande influência no comportamento mecânico dos maciços rochosos e na resposta destes às solicitações atuantes.

A influência da água manifesta-se de várias formas, nomeadamente: reduz a resistência da matriz rochosa em materiais brandos e porosos (e.g., siltitos e calcarenitos); reduz as tensões efetivas, reduzindo, desta forma, a resistência ao corte ao longo dos planos de descontinuidade; promove a meteorização química e física da matriz rochosa e das paredes das descontinuidades, reduzindo o seu ângulo de atrito e a resistência ao corte; é um agente erosivo, promovendo a erosão superficial e interna dos maciços, arrastando os materiais finos e criando vazios na sua estrutura.

A influência da água é, quase sempre, avaliada através dos caudais de percolação observados em ressurgências na face das arribas. No entanto, esses caudais podem não traduzir necessariamente as tensões intersticiais instaladas nas descontinuidades. Em maciços pouco permeáveis, com descontinuidades fechadas ou enchimentos de natureza argilosa, um pequeno caudal de descarga pode estar relacionado com tensões intersticiais mais levadas do que um caudal de descarga elevado num maciço rochoso com elevada permeabilidade.

\section{Exposição às ondas (P10)}

Em termos de intensidade e frequência de atuação, a ondulação é tida como um dos agentes de erosão mais importante, havendo numerosos estudos (e.g., A. S. Trenhaile, 1997; USGS, 2004; T. Sunamura, 1992; P. Budetta et al., 2008) a salientar o seu papel nas relações de causa-efeito que existem entre a infraescavação da base das arribas, o arranque de blocos e a consequente instabilidade e recuo da orla costeira.

A sua atuação é modulada pelas marés, variando a sua capacidade de atuação em função de numerosos parâmetros, nomeadamente: energia da onda; orientação da orla costeira; resistência e erodibilidade do maciço exposto; taxa de varrimento dos detritos depositados na base da arriba; presença ou ausência de uma praia na base da arriba; estabilidade e resiliência da plataforma de abrasão; batimetria adjacente; e fornecimento de material arenoso à plataforma litoral a partir do fundo marinho próximo.

\section{Histórico de eventos de instabilidade (P11)}

Os eventos de instabilidade pretéritos constituem um importante indicador de que pode existir no setor costeiro em apreço um ou vários fatores críticos suscetíveis de condicionarem e desencadearem futuros eventos de instabilidade.

A partir da observação e retroanálise dos eventos de instabilidade pretéritos podem deduzir-se quais foram os fatores (ou combinação de fatores) que condicionaram e desencadearam essas roturas, permitindo prever de que forma os fatores críticos se poderão combinar novamente para produzir futuras roturas. Os dados de eventos de instabilidade pretéritos também permitem 
a avaliação de alguns dos parâmetros que caracterizam a perigosidade dos movimentos (e.g., a frequência, o volume, a velocidade, a trajetória e o alcance dos blocos). No entanto, é preciso ter em conta que, no caso das rochas brandas, a agitação marítima pode desintegrar e remover os blocos rochosos num espaço de tempo relativamente curto, sem dar lugar à formação de um tálus de deposição.

\section{Aplicação do método Rock Engineering System (RES)}

Para identificar e quantificar a importância relativa dos parâmetros suscetíveis de condicionarem o comportamento das arribas, percebendo as interações existentes entre esses parâmetros, foi utilizado o método RES (J. A. Hudson, 1992). Trata-se de um método modulável, onde o número e o tipo de parâmetros utilizados podem ser escolhidos em função dos objetivos pretendidos, de forma a hierarquizar o seu grau de importância e influência, através da atribuição de pesos.

No método RES um sistema é definido como um objeto mais ou menos complexo, que reage de uma determinada forma aos parâmetros de entrada (as causas - C), para produzir um sinal de saída (os efeitos - E). A abordagem a utilizar consiste em definir todos os parâmetros que se julguem importantes para o sistema em análise, colocando-os numa forma matricial, na diagonal principal, ficando os termos fora da diagonal principal reservados para a consideração das interações ou mecanismos existentes entre esses parâmetros. Desta forma, a matriz de interações constitui uma ferramenta para representar os principais parâmetros que influenciam um determinado sistema e os mecanismos envolvidos entre esses parâmetros, quantificando a influência que eles têm sobre o sistema (C), bem como a influência que o sistema tem sobre eles $(E)$.

Uma vez definidos os 11 parâmetros que constituem a diagonal principal da matriz, procedeu-se à identificação e descrição das interações binárias entre eles, lidas no sentido horário, onde o modo como um determinado parâmetro $A$ influencia o $B$, não é necessariamente o mesmo como B influencia A (fig. 3). Para as arribas rochosas da orla costeira do Barlavento Algarvio a matriz de interações $11 \times 11$ foi subdividida em 4 submatrizes (fig. 4 a 7), de forma a tornar a sua leitura percetível.

Definida a matriz de interações $11 \times 11$, a sua codificação foi feita quantificando a intensidade de cada interação de forma determinística, com base no método ESQ (expert semi-quantitative). Os valores numéricos de codificação variaram entre 0 e 4: i) 0 - sem interação; ii) 1 - interação fraca; iii) 2 - interação média; iv) 3 interação forte; v) 4 - interação crítica.

Com a matriz de interações codificada determinam-se os valores causa e efeito de cada parâmetro (fig. 8).

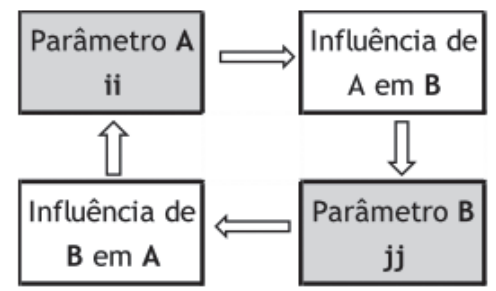

Fig. 3 - Representação esquemática de uma matriz de interações $2 \times 2$, com dois parâmetros A e B.

Fig. 3 - Schematic representation of a $2 \times 2$ interaction matrix with two parameters $A$ and $B$.

Somando os valores das interações existentes ao longo de uma linha da matriz, referente a um determinado parâmetro $P_{i}$, obtém-se um valor designado por causa, que representa a influência de $P_{i}$ nos restantes parâmetros do sistema. Por outro lado, somando os valores das interações existentes ao longo de uma coluna, obtém-se um valor designado por efeito, o qual representa a influência dos outros parâmetros em $P_{i}$.

O parâmetro dominante é aquele que apresenta o maior valor da diferença causa-feito (C-E), o que significa que esse parâmetro exerce uma forte influência sobre o sistema, mas que recebe uma reduzida influência deste. Assim, quando um sistema apresenta um ou mais parâmetros dominantes, pode ser útil adotar medidas estruturais ou outras, que minimizem a sua influência na instabilidade do sistema.

O parâmetro com maior intensidade de interação será o que tiver o maior valor da soma causa+efeito $(\mathrm{C}+\mathrm{E})$. É um parâmetro que exerce uma forte influência sobre o sistema e que o sistema também exerce uma forte influência sobre ele. Desta forma, a intensidade de interação $(\mathrm{C}+\mathrm{E})$ descreve a tendência do sistema para a instabilidade; dado que, quanto maior for o número de parâmetros interativos, mais instável é o sistema, havendo uma maior probabilidade de uma pequena variação num desses parâmetros poder afetar significativamente o comportamento do sistema.

Alguns dos parâmetros do sistema são descritos qualitativamente, enquanto que outros são quantitativos e apresentam diferentes unidades, razão pela qual não é possível utilizar os valores efetivos de cada parâmetro para calcular o índice de instabilidade $\left(I_{j}\right)$ das arribas, sendo necessário atribuir pesos às diferentes classes de valores de parâmetros. Para tal, foram estabelecidas 3 classes de valores, às quais foram atribuídos os pesos (TABELA I): 0 - neutro; 1 - contributivo; e 2 - essencial para a instabilidade.

O coeficiente de ponderação $a_{i}(\%)$ de cada parâmetro $P_{i}$, que expressa proporcionalmente a influência de cada parâmetro na rotura da arriba, é calculado com base no valor da intensidade de interação $(C+E)$, de acordo com a seguinte expressão: 


$$
a_{i}(\%)=\frac{1}{2} \frac{(C+E)}{\sum_{i}^{11} C+\sum_{i}^{11} E} \times 100
$$

$O$ índice de instabilidade $\left(I I_{j}\right)$ das arribas é calculado através da expressão (J. A. Hudson, 1992):

$$
I I_{j}=\sum_{i}^{11} a_{i} \times P_{i j}
$$

em que $i$ se refere aos parâmetros do sistema (de 1 a 11), $j$ refere-se à arriba analisada, $a_{i}$ é o coeficiente de ponderação de cada parâmetro, e $P_{i j}$ é o peso atribuído à classe cada parâmetro, o qual assume valores diferentes em arribas distintas.

$\mathrm{O}$ índice de instabilidade $\left(I I_{j}\right)$ expressa a instabilidade potencial inerente a cada arriba, variando entre 0 e o valor máximo de 100 , sendo tanto mais elevado quanto maior for a instabilidade potencial. Os valores de $\mathrm{II}_{\mathrm{j}}$ foram agrupados em 3 classes de suscetibilidade à ocorrência de eventos de instabilidade por movimentos de massa (TABELA II): baixa suscetibilidade $(<41 \%)$; média suscetibilidade (41-60\%); elevada suscetibilidade $(>60 \%)$.

\section{Resultados e discussão}

Os resultados obtidos (TABELA III e fig. 9) evidenciam que os parâmetros dominantes (C-E), suscetíveis de exerceremuma forte influência sobre os outros parâmetros do sistema, mas
TABeLA II - Classes de suscetibilidade.

TABLE II - Susceptibility classes.

\begin{tabular}{|c|c|c|}
\hline Classe & Intervalo & Classificação \\
\hline I & $<41 \%$ & $\begin{array}{c}\text { Baixa suscetibilidade - Arriba } \\
\text { estável }\end{array}$ \\
\hline II & $41-60 \%$ & $\begin{array}{c}\text { Média suscetibilidade - Arriba } \\
\text { parcialmente estável }\end{array}$ \\
\hline III & $>60 \%$ & $\begin{array}{c}\text { Elevada suscetibilidade - Arriba } \\
\text { instável }\end{array}$ \\
\hline
\end{tabular}

que recebem uma reduzida influência destes, são a variação vertical de fácies (P3), a orientação das descontinuidades relativamente à face da arriba $(\mathrm{P} 8)$ e a exposição às ondas (P10). Estes resultados estão em conformidade com o facto da queda de blocos rochosos de uma arriba ser um processo que envolve o desprendimento de blocos individualizados por superfícies de descontinuidade onde os movimentos tangenciais são nulos ou reduzidos, seguidos de queda. Os planos de rotura podem ser descontinuidades estruturais ou fendas de tração geradas nos blocos colocados em consola pela erosão diferencial de estratos que exibem distintas características de resistência e erodibilidade, mas também podem ser geradas em resultado da infraescavação basal e do descalçamento de blocos promovido pela abrasão marinha.

Os valores de causa e efeito dos 11 parâmetros que constituem o sistema foram usados como coordenadas e

TABELA I - Classificação e pesos atribuídos aos 11 parâmetros.

\begin{tabular}{|c|c|c|c|}
\hline Classes & 0 & 1 & 2 \\
\hline P1 & $<5,0 \mathrm{~m}$ & $5,0-20 m$ & $>20 \mathrm{~m}$ \\
\hline P2 & $<30^{\circ}$ & $30^{\circ}-70^{\circ}$ & $>70^{\circ}$ \\
\hline P3 & Ausente & $\begin{array}{c}\text { Maciço estratificado, com ligeira } \\
\text { heterogeneidade de características } \\
\text { de resistência e erodibilidade }\end{array}$ & $\begin{array}{l}\text { Alternância de materiais } \\
\text { de diferente litologia e } \\
\text { competência, blocos em } \\
\text { consola devido à erosão } \\
\text { diferencial }\end{array}$ \\
\hline P4 & $>25 \mathrm{MPa}$ & $5.0-25 \mathrm{MPa}$ & $<5.0 \mathrm{MPa}$ \\
\hline P5 & Ausente & Medianamente alterado e carsificado & Muito alterado e carsificado \\
\hline P6 & 1, espaçada & 1-3, medianamente espaçadas & >3, pouco espaçadas \\
\hline P7 & $\begin{array}{l}\text { Não contínuas, muito rugosas, } \\
\text { fechadas e paredes sãs }\end{array}$ & $\begin{array}{c}\text { Ligeiramente rugosas, abertura } \\
<1 \mathrm{~mm} \text { e paredes ligeiramente } \\
\text { alteradas }\end{array}$ & $\begin{array}{l}\text { Enchimento mole com } \\
\text { espessura }>5 \mathrm{~mm} \text { ou diaclases } \\
\text { com abertura }>5 \mathrm{~mm}\end{array}$ \\
\hline P8 & $\begin{array}{c}\text { O ângulo entre a direção } \\
\text { das descontinuidades e da } \\
\text { arriba é }>20^{\circ} \text {. A inclinação das } \\
\text { descontinuidades é }<30^{\circ}\end{array}$ & $\begin{array}{l}\text { O ângulo entre a direção das } \\
\text { descontinuidades e da arriba } \\
\text { é } 10^{\circ} \text { a } 20^{\circ} \text {. A inclinação das } \\
\text { descontinuidades é de } 30^{\circ} \text { a } 35^{\circ}\end{array}$ & $\begin{array}{c}\text { O ângulo entre a direção } \\
\text { das descontinuidades e da } \\
\text { arriba é }<10^{\circ} \text {. A inclinação das } \\
\text { descontinuidades é }>35^{\circ}\end{array}$ \\
\hline P9 & Ausente & Humidade & Fluxo \\
\hline P10 & Ausente & Esporádica & Persistente \\
\hline P11 & Inativa & Instabilidade esporádica & Instabilidade frequente \\
\hline
\end{tabular}

TABLE I - Classification and rating of 11 parameters. 
0 - Sem interação;

1 - Interação fraca;

2 - Interação média;

3 - Interação forte;

4 - Interação crítica.

\begin{tabular}{|c|c|c|c|c|c|c|c|c|c|c|}
\hline $\mathrm{P} 1$ & 3 & 0 & 0 & 0 & 0 & 0 & 0 & 0 & 0 & 3 \\
\hline 3 & $\mathrm{P} 2$ & 0 & 0 & 0 & 0 & 0 & 0 & 1 & 0 & 3 \\
\hline 1 & 3 & $\mathrm{P} 3$ & 4 & 3 & 2 & 2 & 0 & 2 & 0 & 4 \\
\hline 1 & 2 & 0 & $\mathrm{P} 4$ & 0 & 1 & 1 & 0 & 0 & 0 & 2 \\
\hline 3 & 2 & 0 & 4 & $\mathrm{P} 5$ & 3 & 1 & 0 & 2 & 0 & 4 \\
\hline 3 & 3 & 0 & 2 & 4 & $\mathrm{P} 6$ & 0 & 0 & 2 & 0 & 3 \\
\hline 1 & 3 & 0 & 1 & 2 & 0 & $\mathrm{P} 7$ & 0 & 4 & 0 & 3 \\
\hline 3 & 3 & 0 & 0 & 2 & 0 & 0 & $\mathrm{P} 8$ & 2 & 0 & 4 \\
\hline 1 & 1 & 0 & 3 & 4 & 0 & 1 & 0 & $\mathrm{P9}$ & 0 & 3 \\
\hline 1 & 4 & 0 & 3 & 3 & 1 & 1 & 0 & 1 & $\mathrm{P} 10$ & 3 \\
\hline 4 & 4 & 0 & 0 & 0 & 1 & 0 & 0 & 1 & 3 & $\mathrm{P} 11$ \\
\hline
\end{tabular}

\begin{tabular}{|c|c|c|c|c|c|}
\hline $\begin{array}{c}\text { P1 - Altura da } \\
\text { arriba }\end{array}$ & $\begin{array}{c}\text { Quando a altura da } \\
\text { arriba aumenta, a } \\
\text { inclinação estável } \\
\text { diminui }\end{array}$ & Sem interação & Sem interação & Sem interação & Sem interação \\
\hline $\begin{array}{c}\text { As arribas } \\
\text { subverticais ou } \\
\text { com inclinação } \\
\text { negativa, a altura } \\
\text { estável diminui }\end{array}$ & $\begin{array}{c}\text { P2 - Inclinação da } \\
\text { arriba }\end{array}$ & Sem interação & Sem interação & Sem interação & Sem interação \\
\hline $\begin{array}{c}\text { A variação } \\
\text { vertical de fácies } \\
\text { condiciona a altura } \\
\text { estável }\end{array}$ & $\begin{array}{l}\text { O perfil transversal } \\
\text { da arriba varia em } \\
\text { função da fácies } \\
\text { geológica }\end{array}$ & $\begin{array}{c}\text { P3 - Variação } \\
\text { vertical de fácies }\end{array}$ & $\begin{array}{l}\text { Diferentes } \\
\text { fácies geológicas } \\
\text { têm diferente } \\
\text { resistência à } \\
\text { compressão } \\
\text { uniaxial }\end{array}$ & $\begin{array}{l}\text { A fácies geológica } \\
\text { condiciona a } \\
\text { alteração e } \\
\text { dissolução cársica } \\
\text { dos maciços }\end{array}$ & $\begin{array}{l}\text { O } \mathrm{n}^{\circ} \text { de famílias de } \\
\text { descontinuidade } \mathrm{e} \\
\text { o seu espaçamento } \\
\text { variam em função } \\
\text { da fácies geológica }\end{array}$ \\
\hline $\begin{array}{c}\text { Nos materiais } \\
\text { brandos a altura } \\
\text { estável da arriba } \\
\text { diminui }\end{array}$ & $\begin{array}{c}\text { Nos materiais } \\
\text { brandos a } \\
\text { inclinação estável } \\
\text { da arriba diminui }\end{array}$ & Sem interação & $\begin{array}{l}\text { P4 - Resistência } \\
\text { à compressão } \\
\text { uniaxial da matriz } \\
\text { rochosa }\end{array}$ & Sem interação & $\begin{array}{l}\text { Rochas brandas } \\
\text { podem apresentar } \\
\text { um maior } n^{\circ} \text { de } \\
\text { descontinuidades } \\
\text { induzidas }\end{array}$ \\
\hline $\begin{array}{l}\text { Nos maciços muito } \\
\text { alterados e/ } \\
\text { ou carsificados, } \\
\text { a altura estável } \\
\text { diminui }\end{array}$ & $\begin{array}{l}\text { Nos maciços muito } \\
\text { alterados e/ou } \\
\text { carsificados, a } \\
\text { inclinação estável } \\
\text { diminui }\end{array}$ & Sem interação & $\begin{array}{c}\text { A alteração diminui } \\
\text { a resistência } \\
\text { à compressão } \\
\text { uniaxial da matriz } \\
\text { rochosa }\end{array}$ & $\begin{array}{l}\text { P5 - Alteração e } \\
\text { dissolução cársica }\end{array}$ & $\begin{array}{c}\text { Os processos } \\
\text { de alteração e } \\
\text { dissolução cársica } \\
\text { podem gerar } \\
\text { descontinuidades } \\
\text { secundárias }\end{array}$ \\
\hline $\begin{array}{l}\text { Nos maciços muito } \\
\text { compartimentados } \\
\text { a altura estável da } \\
\text { arriba diminui }\end{array}$ & $\begin{array}{c}\text { Nos maciços muito } \\
\text { compartimentados } \\
\text { a inclinação } \\
\text { estável da arriba } \\
\text { diminui }\end{array}$ & Sem interação & $\begin{array}{c}\text { Nos maciços muito } \\
\text { compartimentados } \\
\text { a resistência da } \\
\text { matriz rochosa } \\
\text { diminui }\end{array}$ & $\begin{array}{l}\text { A fracturação } \\
\text { aumenta a } \\
\text { permeabilidade e } \\
\text { o fluxo de água, } \\
\text { favorecendo } \\
\text { a alteração e } \\
\text { dissolução cársica }\end{array}$ & $\begin{array}{c}\mathrm{P} 6-\mathrm{N}^{\circ} \text { de } \\
\text { famílias e } \\
\text { espaçamento das } \\
\text { descontinuidades }\end{array}$ \\
\hline
\end{tabular}

Fig. 4 - Parte superior esquerda da matriz de interações $11 \times 11$.

Fig. 4 - The top-left quarter of the 11x11 interaction matrix. 


\section{territorium 24}

\begin{tabular}{|c|c|c|c|c|c|c|c|c|c|c|c|c|}
\hline 0 & 0 - Sem interação; & P1 & 3 & 0 & 0 & 0 & 0 & 0 & 0 & 0 & 0 & 3 \\
\hline & \multirow{2}{*}{1 - Interação fraca; } & 3 & P2 & 0 & 0 & 0 & 0 & 0 & 0 & 1 & 0 & 3 \\
\hline 1 & & 1 & 3 & P3 & 4 & 3 & 2 & 2 & 0 & 2 & 0 & 4 \\
\hline 2 & \multirow{2}{*}{2 - Interação média; } & 1 & 2 & 0 & P4 & 0 & 1 & 1 & 0 & 0 & 0 & 2 \\
\hline & & 3 & 2 & 0 & 4 & P5 & 3 & 1 & 0 & 2 & 0 & 4 \\
\hline 3 & 3 - Interação forte; & 3 & 3 & 0 & 2 & 4 & P6 & 0 & 0 & 2 & 0 & 3 \\
\hline \multirow{5}{*}{4} & \multirow{5}{*}{4 - Interação crítica. } & 1 & 3 & 0 & 1 & 2 & 0 & P7 & 0 & 4 & 0 & 3 \\
\hline & & 3 & 3 & 0 & 0 & 2 & 0 & 0 & P8 & 2 & 0 & 4 \\
\hline & & 1 & 1 & 0 & 3 & 4 & 0 & 1 & 0 & P9 & 0 & 3 \\
\hline & & 1 & 4 & 0 & 3 & 3 & 1 & 1 & 0 & 1 & P10 & 3 \\
\hline & & 4 & 4 & 0 & 0 & 0 & 1 & 0 & 0 & 1 & 3 & P11 \\
\hline
\end{tabular}

\begin{tabular}{|c|c|c|c|c|}
\hline Sem interação & Sem interação & Sem interação & Sem interação & $\begin{array}{c}\text { O estado de } \\
\text { tensão aumenta } \\
\text { com a altura da } \\
\text { arriba, aumentado } \\
\text { a instabilidade } \\
\text { potencial }\end{array}$ \\
\hline Sem interação & Sem interação & $\begin{array}{l}\text { A inclinação } \\
\text { afeta a taxa } \\
\text { de infiltração e } \\
\text { o escoamento } \\
\text { superficial }\end{array}$ & Sem interação & $\begin{array}{l}\text { A inclinação afeta } \\
\text { a suscetibilidade } \\
\text { à ocorrência } \\
\text { de eventos de } \\
\text { instabilidade }\end{array}$ \\
\hline $\begin{array}{l}\text { A condição das } \\
\text { descontinuidades } \\
\text { pode variar em } \\
\text { função da fácies } \\
\text { geológica }\end{array}$ & Sem interação & $\begin{array}{l}\text { As caraterísticas } \\
\text { geológicas variam } \\
\text { em função da } \\
\text { fácies geológica }\end{array}$ & Sem interação & $\begin{array}{c}\text { A heterogeneidade } \\
\text { das características } \\
\text { de resistência e } \\
\text { durabilidade dá } \\
\text { origem a blocos } \\
\text { posicionados em } \\
\text { consola }\end{array}$ \\
\hline $\begin{array}{l}\text { Nas rochas duras } \\
\text { os planos de } \\
\text { descontinuidade } \\
\text { podem } \\
\text { apresentar maior } \\
\text { continuidade }\end{array}$ & Sem interação & Sem interação & Sem interação & $\begin{array}{l}\text { Rochas brandas } \\
\text { apresentam } \\
\text { maior frequência } \\
\text { de eventos de } \\
\text { instabilidade }\end{array}$ \\
\hline $\begin{array}{l}\text { A alteração } \\
\text { e dissolução } \\
\text { aumentam } \\
\text { a abertura e } \\
\text { diminuem a } \\
\text { rugosidade das } \\
\text { descontinuidades }\end{array}$ & Sem interação & $\begin{array}{l}\text { O carso aumenta a } \\
\text { permeabilidade e } \\
\text { o fluxo de água }\end{array}$ & Sem interação & $\begin{array}{c}\text { A captura e o } \\
\text { desmantelamento } \\
\text { do carso pela } \\
\text { erosão marinha } \\
\text { geram movimentos } \\
\text { de massa }\end{array}$ \\
\hline Sem interação & Sem interação & $\begin{array}{l}\text { A fracturação } \\
\text { aumenta a } \\
\text { permeabilidade } \\
\text { dos maciços }\end{array}$ & Sem interação & $\begin{array}{l}\text { Os maciços mais } \\
\text { compartimentados } \\
\text { apresentam uma } \\
\text { maior frequência } \\
\text { de eventos de } \\
\text { instabilidade }\end{array}$ \\
\hline
\end{tabular}

Fig. 5 - Parte superior direita da matriz de interações $11 \times 11$.

Fig. 5 - The top-right quarter of the $11 \times 11$ interaction matrix. 
representados num diagrama causa-efeito (fig. 9), sendo a intensidade de interação de cada parâmetro medida ao longo da linha diagonal $\mathrm{C}=\mathrm{E}$. Para avaliar se um determinado parâmetro é dominante ou subordinado, é medida a distância entre o ponto representativo desse parâmetro e a linha $\mathrm{C}=\mathrm{E}$, na perpendicular a esta.

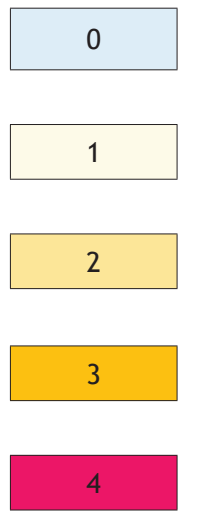

0 - Sem interação;

1 - Interação fraca;

2 - Interação média;

3 - Interação forte;

4 - Interação crítica.

\begin{tabular}{|c|c|c|c|c|c|c|c|c|c|c|}
\hline $\mathrm{P} 1$ & 3 & 0 & 0 & 0 & 0 & 0 & 0 & 0 & 0 & 3 \\
\hline 3 & $\mathrm{P} 2$ & 0 & 0 & 0 & 0 & 0 & 0 & 1 & 0 & 3 \\
\hline 1 & 3 & $\mathrm{P} 3$ & 4 & 3 & 2 & 2 & 0 & 2 & 0 & 4 \\
\hline 1 & 2 & 0 & $\mathrm{P} 4$ & 0 & 1 & 1 & 0 & 0 & 0 & 2 \\
\hline 3 & 2 & 0 & 4 & $\mathrm{P} 5$ & 3 & 1 & 0 & 2 & 0 & 4 \\
\hline 3 & 3 & 0 & 2 & 4 & $\mathrm{P} 6$ & 0 & 0 & 2 & 0 & 3 \\
\hline 1 & 3 & 0 & 1 & 2 & 0 & $\mathrm{P} 7$ & 0 & 4 & 0 & 3 \\
\hline 3 & 3 & 0 & 0 & 2 & 0 & 0 & $\mathrm{P} 8$ & 2 & 0 & 4 \\
\hline 1 & 1 & 0 & 3 & 4 & 0 & 1 & 0 & $\mathrm{P} 9$ & 0 & 3 \\
\hline 1 & 4 & 0 & 3 & 3 & 1 & 1 & 0 & 1 & $\mathrm{P} 10$ & 3 \\
\hline 4 & 4 & 0 & 0 & 0 & 1 & 0 & 0 & 1 & 3 & $\mathrm{P} 11$ \\
\hline
\end{tabular}

\begin{tabular}{|c|c|c|c|c|c|}
\hline $\begin{array}{l}\text { Descontinuidades } \\
\text { persistentes, } \\
\text { planas e com } \\
\text { preenchimento } \\
\text { argiloso, reduzem } \\
\text { a altura estável }\end{array}$ & $\begin{array}{c}\text { A condição das } \\
\text { descontinuidades } \\
\text { controla a } \\
\text { inclinação estável } \\
\text { da arriba }\end{array}$ & Sem interação & $\begin{array}{l}\text { Descontinuidades } \\
\text { persistentes e } \\
\text { abertas favorecem } \\
\text { a diminuição da } \\
\text { resistência da } \\
\text { matriz rochosa }\end{array}$ & $\begin{array}{l}\text { Descontinuidades } \\
\text { persistentes e } \\
\text { abertas potenciam } \\
\text { a alteração e } \\
\text { dissolução cársica }\end{array}$ & Sem interação \\
\hline $\begin{array}{c}\text { As } \\
\text { descontinuidades } \\
\text { com orientação } \\
\text { desfavorável } \\
\text { condicionam a } \\
\text { altura estável }\end{array}$ & $\begin{array}{l}\text { A orientação das } \\
\text { descontinuidades } \\
\text { condiciona a } \\
\text { inclinação estável }\end{array}$ & Sem interação & Sem interação & $\begin{array}{c}\text { As fraturas } \\
\text { subverti cais são } \\
\text { favoráveis ao } \\
\text { desenvolvimento } \\
\text { de algares }\end{array}$ & Sem interação \\
\hline $\begin{array}{l}\text { As tensões } \\
\text { intersticiais e } \\
\text { as forças de } \\
\text { percolaçãao } \\
\text { reduzem a altura } \\
\text { estável }\end{array}$ & $\begin{array}{c}\text { As tensões } \\
\text { intersticiais e } \\
\text { as forças de } \\
\text { percolação } \\
\text { reduzem a } \\
\text { inclinação estável }\end{array}$ & Sem interação & $\begin{array}{c}\text { Reduz a resistência } \\
\text { da matriz rochosa, } \\
\text { sobretudo em } \\
\text { materiais brandos }\end{array}$ & $\begin{array}{l}\text { A presença e o } \\
\text { fluxo de água } \\
\text { potenciam a } \\
\text { alteração e } \\
\text { dissolução cársica }\end{array}$ & Sem interação \\
\hline $\begin{array}{c}\text { A ondulação } \\
\text { incidente diminui } \\
\text { a altura estável }\end{array}$ & $\begin{array}{c}\text { Infraescavação } \\
\text { (entalhe basal ou } \\
\text { sapagem) da base } \\
\text { das arribas }\end{array}$ & Sem interação & $\begin{array}{l}\text { A saturação reduz } \\
\text { a resistência da } \\
\text { matriz rochosa, } \\
\text { sobretudo em } \\
\text { materiais brandos } \\
\text { e porosos }\end{array}$ & $\begin{array}{l}\text { A interface água } \\
\text { doce-salgada } \\
\text { constitui uma } \\
\text { zona geoquímica } \\
\text { favorável à } \\
\text { alteração e } \\
\text { dissolução cársica }\end{array}$ & $\begin{array}{c}\text { A ondulação } \\
\text { incidente provoca } \\
\text { fadiga mecânica } \\
\text { dos maciços }\end{array}$ \\
\hline $\begin{array}{l}\text { Os eventos de } \\
\text { instabilidade } \\
\text { podem reduzir a } \\
\text { altura da arriba }\end{array}$ & $\begin{array}{l}\text { Os eventos de } \\
\text { instabilidade } \\
\text { alteram o perfil } \\
\text { transversal da } \\
\text { arriba }\end{array}$ & Sem interação & Sem interação & Sem interação & $\begin{array}{l}\text { Os processos de } \\
\text { instabilidade } \\
\text { podem provocar } \\
\text { fracturação dos } \\
\text { maciços }\end{array}$ \\
\hline
\end{tabular}

Fig. 6 - Parte inferior esquerda da matriz de interações $11 \times 11$.

Fig. 6 - The bottom-left quarter of the 11x11 interaction matrix. 
O parâmetro subordinado, no sentido em que exerce uma menor influência sobre os outros parâmetros do sistema, mas que recebe uma forte influência destes, é inclinação da arriba (P2).
0 parâmetro com maior intensidade de interação $(C+E)$, que exerce uma forte influência sobre os outros parâmetros do sistema e sobre o qual os restantes parâmetros também exercem uma forte influência,

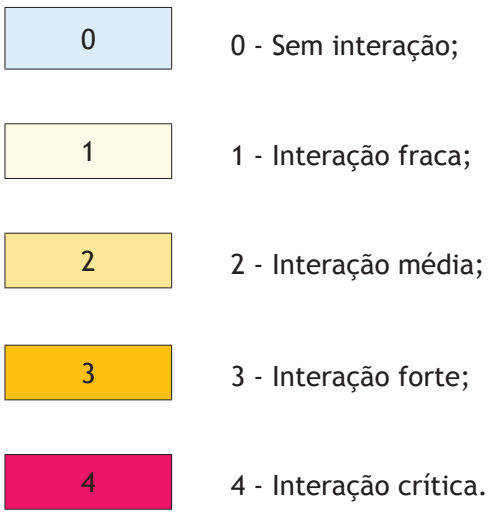

\begin{tabular}{|c|c|c|c|c|c|c|c|c|c|c|}
\hline $\mathrm{P} 1$ & 3 & 0 & 0 & 0 & 0 & 0 & 0 & 0 & 0 & 3 \\
\hline 3 & $\mathrm{P} 2$ & 0 & 0 & 0 & 0 & 0 & 0 & 1 & 0 & 3 \\
\hline 1 & 3 & $\mathrm{P} 3$ & 4 & 3 & 2 & 2 & 0 & 2 & 0 & 4 \\
\hline 1 & 2 & 0 & $\mathrm{P} 4$ & 0 & 1 & 1 & 0 & 0 & 0 & 2 \\
\hline 3 & 2 & 0 & 4 & $\mathrm{P} 5$ & 3 & 1 & 0 & 2 & 0 & 4 \\
\hline 3 & 3 & 0 & 2 & 4 & $\mathrm{P} 6$ & 0 & 0 & 2 & 0 & 3 \\
\hline 1 & 3 & 0 & 1 & 2 & 0 & $\mathrm{P} 7$ & 0 & 4 & 0 & 3 \\
\hline 3 & 3 & 0 & 0 & 2 & 0 & 0 & $\mathrm{P} 8$ & 2 & 0 & 4 \\
\hline 1 & 1 & 0 & 3 & 4 & 0 & 1 & 0 & $\mathrm{P} 9$ & 0 & 3 \\
\hline 1 & 4 & 0 & 3 & 3 & 1 & 1 & 0 & 1 & $\mathrm{P} 10$ & 3 \\
\hline 4 & 4 & 0 & 0 & 0 & 1 & 0 & 0 & 1 & 3 & $\mathrm{P} 11$ \\
\hline
\end{tabular}

\begin{tabular}{|c|c|c|c|c|}
\hline $\begin{array}{l}\text { P7 - Condição das } \\
\text { descontinuidades } \\
\text { (Persistência, } \\
\text { Rugosidade, } \\
\text { Abertura e } \\
\text { Enchimento) }\end{array}$ & Sem interação & $\begin{array}{l}\text { A permeabilidade } \\
\text { dos maciços e } \\
\text { a presença de } \\
\text { água dependem } \\
\text { da condição das } \\
\text { descontinuidades }\end{array}$ & Sem interação & $\begin{array}{c}\text { A resistência } \\
\text { ao corte e a } \\
\text { deformabilidade } \\
\text { dos maciços } \\
\text { rochosos } \\
\text { dependem da } \\
\text { condição das } \\
\text { descontinuidades }\end{array}$ \\
\hline Sem interação & $\begin{array}{c}\text { P8 - } \\
\text { Orientação das } \\
\text { descontinuidades } \\
\text { em relação à face } \\
\text { da arriba }\end{array}$ & $\begin{array}{l}\text { A orientação das } \\
\text { descontinuidades } \\
\text { condiciona a } \\
\text { infiltração e o } \\
\text { fluxo de água }\end{array}$ & Sem interação & $\begin{array}{c}\text { Descontinuidades } \\
\text { com orientação } \\
\text { desfavorável } \\
\text { geram condições } \\
\text { de instabilidade }\end{array}$ \\
\hline $\begin{array}{l}\text { Alteração das } \\
\text { descontinuidades e } \\
\text { erosão do material } \\
\text { de enchimento }\end{array}$ & Sem interação & $\begin{array}{l}\text { P9 - Presença de } \\
\text { água subterrânea }\end{array}$ & Sem interação & $\begin{array}{c}\text { Reduz a resistência } \\
\text { ao corte nas } \\
\text { descontinuidades e } \\
\text { a estabilidade das } \\
\text { arribas }\end{array}$ \\
\hline $\begin{array}{c}\text { Desenvolvimento } \\
\text { e abertura das } \\
\text { descontinuidades, } \\
\text { e erosão do } \\
\text { material de } \\
\text { enchimento }\end{array}$ & Sem interação & $\begin{array}{c}\text { Aumenta o grau de } \\
\text { saturação }\end{array}$ & $\begin{array}{l}\text { P10 - Exposição } \\
\text { às ondas }\end{array}$ & $\begin{array}{c}\text { A ondulação } \\
\text { incidente promove } \\
\text { a abrasão e } \\
\text { o arranque e } \\
\text { desprendimento } \\
\text { de blocos }\end{array}$ \\
\hline Sem interação & Sem interação & $\begin{array}{l}\text { A instabilidade } \\
\text { pode alterar } \\
\text { a tensões } \\
\text { intersticiais }\end{array}$ & $\begin{array}{l}\text { Os blocos rochosos } \\
\text { protegem a base } \\
\text { da arriba da } \\
\text { erosão marinha }\end{array}$ & $\begin{array}{l}\text { P11 - Histórico } \\
\text { de eventos de } \\
\text { instabilidade }\end{array}$ \\
\hline
\end{tabular}

Fig. 7 - Parte inferior direita da matriz de interações $11 \times 11$.

Fig. 7 - The bottom-right quarter of the 11x11 interaction matrix. 
exercendo, por esse motivo, uma forte influência sobre a estabilidade das arribas, é a alteração e dissolução cársica (P5).

Nas formações carbonatadas, a alteração e dissolução cársica exerce uma forte influência sobre as características mecânicas dos maciços rochosos, visto que diminui a resistência do material rocha, gera fraturação secundária e promove a abertura das descontinuidades ou aumenta a espessura dos enchimentos. Os outros parâmetros do sistema também exercem uma forte influência sobre a alteração e dissolução cársica, nomeadamente, a variação vertical de fácies (estratigrafia e litologia), a presença e fluxo de água,

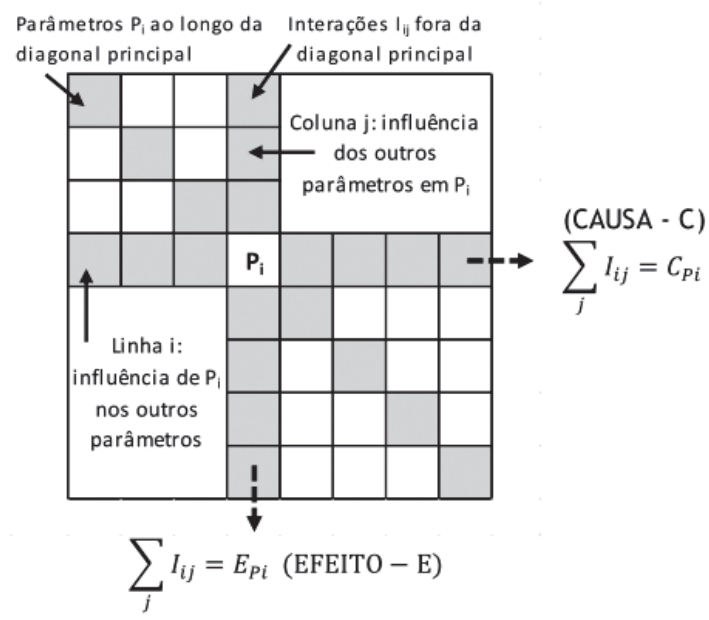

Fig. 8 - Somatório dos valores codificados das interações na linha e coluna que contem cada parâmetro, para obtenção das coordenadas causa (C) e efeito (E) (Fonte: J. A. Hudson, 1992).

Fig. 8 - Summation of coding values in the row and column through each parameter to establish the cause (C) and effect (E) co-ordinates (Source: J. A. Hudson, 1992). o número de famílias de superfícies descontinuidade, o espaçamento e a sua condição (persistência, rugosidade, abertura e enchimento). É, portanto, o parâmetro que mais condiciona a morfologia da costa rochosa e a suscetibilidade à ocorrência de eventos de instabilidade

Foram selecionados 4 setores representativos da orla costeira, 3 dos quais correspondentes a zonas de praia, onde foi avaliado o índice de instabilidade das arribas (TABELA IV). Três destes setores apresentam elevada propensão para a ocorrência de desprendimentos de blocos rochosos, em tempo indeterminado. A arriba que delimita a Praia Nova (Lagoa) encontra-se na fronteira entre a média e a elevada propensão para a ocorrência de desprendimentos. Nesta arriba, os eventos de instabilidade pretéritos, o saneamento de blocos instáveis e o enchimento de praia, melhoraram a sua condição de estabilidade.

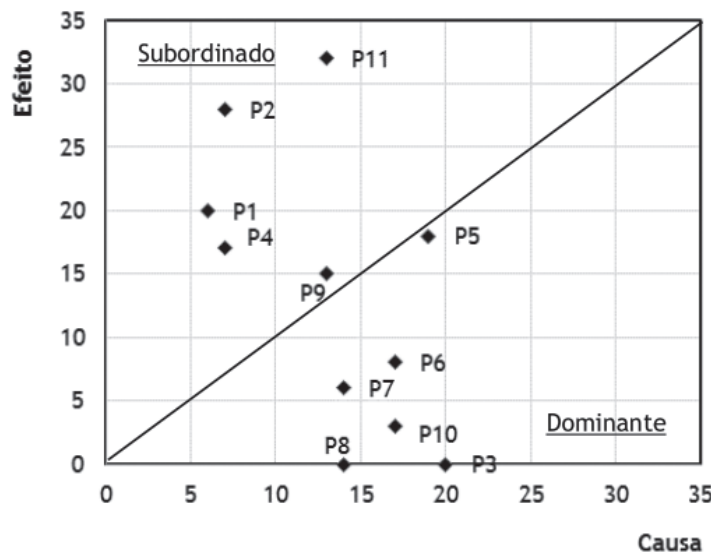

Fig. 9 - Diagrama Causa-Efeito.

Fig. 9 - Cause-Effect diagram.

TABELA III - Matriz de interações binárias codificada para as arribas rochosas.

TABLE III - Matrix of binary interactions coded for the rocky cliffs.

\begin{tabular}{|c|c|c|c|c|c|c|c|c|c|c|c|c|}
\hline P1 & 3 & 0 & 0 & 0 & 0 & 0 & 0 & 0 & 0 & 3 & 6 & \\
\hline 3 & P2 & 0 & 0 & 0 & 0 & 0 & 0 & 1 & 0 & 3 & 7 & \\
\hline 1 & 3 & P3 & 4 & 3 & 2 & 2 & 0 & 2 & 0 & 4 & 21 & \\
\hline 1 & 2 & 0 & P4 & 0 & 1 & 1 & 0 & 0 & 0 & 2 & 7 & \\
\hline 3 & 2 & 0 & 4 & P5 & 3 & 1 & 0 & 2 & 0 & 4 & 19 & $\cup$ \\
\hline 3 & 3 & 0 & 2 & 4 & P6 & 0 & 0 & 2 & 0 & 3 & 17 & $\stackrel{\pi}{\Omega}$ \\
\hline 1 & 3 & 0 & 1 & 2 & 0 & P7 & 0 & 4 & 0 & 3 & 14 & \\
\hline 3 & 3 & 0 & 0 & 2 & 0 & 0 & P8 & 2 & 0 & 4 & 14 & \\
\hline 1 & 1 & 0 & 3 & 4 & 0 & 1 & 0 & P9 & 0 & 3 & 13 & \\
\hline 1 & 4 & 0 & 3 & 3 & 1 & 1 & 0 & 1 & P10 & 3 & 17 & \\
\hline 4 & 4 & 0 & 0 & 0 & 1 & 0 & 0 & 1 & 3 & P11 & 13 & \\
\hline 21 & 28 & 0 & 17 & 18 & 8 & 6 & 0 & 15 & 3 & 32 & 148 & \\
\hline
\end{tabular}

\begin{tabular}{|c|c|c|c|c|c|}
\cline { 2 - 6 } \multicolumn{1}{c|}{} & $\mathrm{C}$ & $\mathrm{E}$ & $\mathrm{C}+\mathrm{E}$ & $\mathrm{C}-\mathrm{E}$ & $\mathrm{a}_{\mathbf{i}(\%)}$ \\
\hline P1 & 6 & 21 & 27 & -15 & 4.56 \\
\hline P2 & 7 & 28 & 35 & -21 & 5.91 \\
\hline P3 & 21 & 0 & 21 & 21 & 3.55 \\
\hline P4 & 7 & 17 & 24 & -10 & 4.05 \\
\hline P5 & 19 & 18 & 37 & 1 & 6.25 \\
\hline P6 & 17 & 8 & 25 & 9 & 4.22 \\
\hline P7 & 14 & 6 & 20 & 8 & 3.38 \\
\hline P8 & 14 & 0 & 14 & 14 & 2.36 \\
\hline P9 & 13 & 15 & 28 & -2 & 4.73 \\
\hline P10 & 17 & 3 & 20 & 14 & 3.38 \\
\hline P11 & 13 & 32 & 45 & -19 & 7.60 \\
\hline
\end{tabular}


TABELA IV - Cálculo do índice de instabilidade.

TABLE IV - Instability index calculations.

\begin{tabular}{|c|c|c|c|c|c|c|c|c|c|c|c|c|}
\hline & $\mathrm{P} 1$ & $\mathrm{P} 2$ & $\mathrm{P} 3$ & $\mathrm{P} 4$ & $\mathrm{P} 5$ & $\mathrm{P} 6$ & $\mathrm{P} 7$ & $\mathrm{P} 8$ & $\mathrm{P} 9$ & $\mathrm{P} 10$ & $\mathrm{P} 11$ & $\mathrm{I}_{\mathrm{j}}(\%)$ \\
\hline $\mathrm{y} \mathrm{a}_{\mathrm{i}}(\%)$ & 4.56 & 5.91 & 3.55 & 4.05 & 6.25 & 4.22 & 3.38 & 2.36 & 4.73 & 3.38 & 7.60 & \\
\hline $\mathrm{S} 1$ & 2 & 2 & 2 & 2 & 1 & 1 & 1 & 0 & 0 & 2 & 2 & 72 \\
\hline $\mathrm{S} 2$ & 1 & 2 & 1 & 2 & 2 & 1 & 2 & 1 & 0 & 1 & 1 & 65 \\
\hline $\mathrm{S} 3$ & 2 & 2 & 2 & 1 & 1 & 1 & 1 & 1 & 0 & 1 & 1 & 59 \\
\hline $\mathrm{S} 4$ & 1 & 2 & 2 & 1 & 1 & 0 & 2 & 2 & 0 & 2 & 2 & 67 \\
\hline
\end{tabular}

S1 - Praia Maria Luísa (Albufeira); S2 - Praia do Castelo (Albufeira); S3 - Praia Nova (Lagoa); S4 - Setor costeiro entre a Praia dos Arrifes e a Marina de Albufeira.

\section{Conclusão}

A instabilidade das arribas da orla costeira é difícil de avaliar e modelar, devido à natureza episódica dos eventos de instabilidade e à complexidade dos mecanismos de instabilidade, que são controladas por uma grande variedade de fatores condicionantes e desencadeantes, dependentes das propriedades geomecânicas dos maciços rochosos e das condições meteorológicas e de agitação marítima.

Nas zonas costeiras alcantiladas, quando o registo histórico dos eventos de instabilidade apresenta muitas lacunas e a informação geotécnica disponível é escassa, aplicação de métodos heurísticos, como é o caso do método RES, constitui uma alternativa eficaz para a avaliação da suscetibilidade à ocorrência de movimentos de massa. Embora não permita avaliar adequadamente a frequência dos eventos de instabilidade (ou a probabilidade de rotura), permite fazer uma seriação das arribas que, em função da sua instabilidade potencial, carecem da realização de estudos geotécnicos de pormenor de forma a avaliar a necessidade de adoção de medidas que diminuam o risco de perda de vidas resultante da queda de blocos rochosos nas zonas de praia.

O conhecimento adequado do local, nomeadamente das características geotécnicas dos maciços expostos pelas arribas, diminui os julgamentos subjetivos na avaliação da importância relativa dos fatores condicionantes da instabilidade e na ponderação das múltiplas interações existentes entre os diferentes parâmetros, tornando os resultados obtidos mais consistentes.

Nas arribas rochosas da orla costeira do Algarve Central, talhadas em formações carbonatadas de idade Miocénica, o parâmetro com maior intensidade de interação, suscetível de exercer uma forte influência sobre a estabilidade das arribas, é a alteração e dissolução cársica (P5). Nos setores onde os maciços rochosos apresentam um carso mais desenvolvido, a resistência à compressão uniaxial da matriz rochosa diminui e o grau de fraturação aumenta, apresentando descontinuidades com uma maior persistência, abertas ou com enchimentos moles, o que facilita a abrasão marinha e aumenta a suscetibilidade à ocorrência de eventos de instabilidade por movimentos de massa, em particular, através de desprendimentos de blocos rochosos e colapsos.

\section{Referências bibliográficas}

AGS - AUSTRALIAN GEOMECHANICS SOCIETY (2007). Guideline for Landslide Susceptibility, Hazard and Risk Zoning for Land Use Management. Australian Geomechanics Society, Australian Geomechanics, Vol 42, No 1.

Ciantia, M. O., Castellanza, R., di Prisco, C. (2014). Experimental study on the water-induced weakening of calcarenites. Rock Mechanics and Rock Engineering 48, p. 441-461.

Corominas, J., Westen, C. V., Frattini, P.,Cascini, L., Malet, J. P., Fotopoulou, S., Catani, F., Eeckhaut, M. V. D., Mavrouli, O., Agliardi, F., Pitilakis, K., Winter, M. G., Pastor, M., Ferlisi, S., Tofani, V., Hervás, J and Smith, J. T. (2013). Recommendations for the quantitative analysis of landslide risk. Bull Eng Geol Environ, November, Published online.

Crosta, G. B., Agliardi, F., Frattini, P., Sosoi, R. (eds) (2012). SafeLand Deliverable 1.1: Landslide triggering mechanisms in Europe - overview and state of the art. Identification of mechanisms and triggers.

Crozier, M., Glade, T. (2005). Landslide hazard and risk: Issues, concepts and approach. In: Glade, T., Anderson, M., Crozier, M.J. (Eds.), Landslide Hazard and Risk. John Wiley and Sons, p.1-40.

Budetta, P., Santo, A., Vivenzio, F. (2008). Landslide hazard mapping along the coastline of the Cilento region (Italy) by means of a GIS-based parameter rating approach. Geomorphology, Volume 94, Issues 3-4, p. 340-352. 
Dussauge-Peisser, C., Helmstetter, A., Grasso, J.-R., Hantz, D., Desvarreux, P., Jeannin, M., Giraud, A. (2002). Probabilistic approach to rock fall hazard assessment: potential of historical data analysis. Natural Hazards and Earth System Sciences, 2, p. 15-26.

EUROSION (2004). Living with coastal erosion in Europe: sediment and space for sustainability. Derectorate General Environment, European Commision, Reports-online 4 e 5.2. Available from: www.eurosion.org.

Fell, R., Corominas, J., Bonnard, C., Cascini, L., Leroi, E., Savage, W. (2008). Guidelines for landslide susceptibility, hazard and risk zoning for land use planning. On behalf of the JTC-1 Joint Technical Committee on Landslides and Engineered Slopes, Engineering Geology 102: p. 85-98 and commentary on p. 99-111.

GEOLOGICAL SOCIETY ENGINEERING GROUP WORKING PARTY (1997). The Description of Rock Masses for Engineering Purposes. Quarterly Journal Engineering Geology 10, pp. 355-388.

Goodman, R. E. (1989). Introduction to Rock Mechanics. 2nd edition, Wiley, New York.

Greiving, S., van Westen, C., Corominas, J., Glade, T., Malet, J., van Asch, T. (2004). Introduction: The components of Risk Governance. In: Mountain risks: From prediction to management and governance. Edited by Theo van Asch, Jordi Corominas, Stefan Greiving, Jean-Philippe Malet and Simone Sterlacchini, Springer, p. 1-27, ISBN 978-94-0076769-0 (eBook).

GROUPE FALAISE (2001). Prévention des mouvements de versants et des instabilités de falaises, groupe falaise, confrontation des méthodes d'étude des éboulements rocheux dans l'arc alpin. Programme Interreg IIC «Falaise » Méditerranée Occidentale et Alpes Latines, 239 p.

Hantz, D. (2007). Contribution à l'évaluation de l'aléa éboulement rocheux Approche multidisciplinaire et multiéchelles. Mémoire de Diplôme d'Habilitation à Diriger des Recherches, Ecole Polytechnique de l'Université de Grenoble 1, 79 p.

Hoek, E., Bray, J.W. (1981). Rock Slope Engineering. Revised Third Edition, Institute of Mining and Metallurgy, London.

Hudson, J.A. (1992). Rock Engineering Systems: Theory and Practice. High Plains Press (JAH), 185 p.

Jaboyedoff, M., Dudt, J. P., Labiouse, V. (2005). An attempt to refine rockfall hazard zoning based on the kinetic energy, frequency and fragmentation degree. Natural Hazards and Earth System Sciences, 5, p. 621-632.
JTC-1 (JOINT INTERNATIONAL TECHNICAL COMMITTEE ON NATURAL SLOPES AND LANDSLIDES - ISSMGE, ISRM, IAEG (2008). Guidelines for Landslide Susceptibility, Hazard and Risk Zoning for Land Use Planning.

Lee, E. M., Hall, J.W., Meadowcroft, I.C. (2001). Coastal cliff recession: the use of probabilistic prediction methods. Geomorphology 40, p. 253-269.

Lee, E.M., \& Jones, D.K.C. (2004). Landslide risk assessment. Thomas Telford, London, $454 \mathrm{p}$.

Lourenço, Luciano (2007). Riscos naturais, antrópicos e mistos, Territorium, $\mathrm{n}^{\circ} 14,109-113$. http://www. uc.pt/fluc/nicif/riscos/Documentacao/Territorium/ T14_artg/T14NNR01.pdf.

Pantelidis, L. (2009). Rock slope stability assessment through rock mass classification systems. International Journal of Rock Mechanics \& Mining Sciences, 46, p. 315-325.

Popescu, M. (1994). A suggested method for reporting landslide causes. Bulletin of the International Association of Engineering Geology, 50, p.71-74.

Rebelo, Fernando (2010). Geografia Física e Riscos Naturais. Coimbra, Imprensa da Universidade, 215 p. Disponível em: https://digitalis.uc.pt/pt-pt/livro/ geografia_f\%C3\%ADsica_e_riscos_naturais.

Sunamura, T. (1992). Geomorphology of Rocky Coasts. J.Wiley \& Sons, Nova lorque, 302 p.

Teixeira, S. B. (2014). Coastal hazards from slope mass movements: Analysis and management approach on the Barlavento Coast, Algarve, Portugal. Ocean \& Coastal Management (102), p. 285-293.

Trenhaile, A. S. (1997). Coastal dynamics and landforms. Oxford University Press, Oxford UK, 366 p.

USGS - UNITED STATES GEOLOGICAL SURVEY (2004). Formation, evolution, and stability of coastal cliffs: status and trends. Professional Paper 1693, Edited by Monty A. Hampton and Gary B. Griggs, U.S. Department of the Interior, U.S. Geological Survey, Denver, 123 p.

Van Westen, C. J. (ed) (2011). Multi-hazard risk assessment: RiskCity. Distance education course, Guide book. United Nations University - ITC School on Disaster Geoinformation Management (UNU-ITC DGIM).

Vengeon, J. M., Hantz, D., Dussauge, C. (2001). Prédictibilité des éboulements rocheux: approche probabiliste par combinaison d'études historiques et géomécaniques. Revue Francaise de Géotechnique, 95/96, p. 143-154. 